\title{
Climate predictability experiments with a general circulation model
}

\author{
L. Bengtsson, K. Arpe, E. Roeckner, U. Schulzweida \\ Max Planck Institut für Meteorologie, Bundesstrasse 55, D-20146 Hamburg, Germany \\ Received: 18 October 1994 / Accepted: 7 November 1995
}

\begin{abstract}
The atmospheric response to the evolution of the global sea surface temperatures from 1979 to 1992 is studied using the Max-Planck-Institut 19 level atmospheric general circulation model, ECHAM3 at T 42 resolution. Five separate 14-year integrations are performed and results are presented for each individual realization and for the ensemble-averaged response. The results are compared to a 30-year control integration using a climate monthly mean state of the sea surface temperatures and to analysis data. It is found that the ECHAM3 model, by and large, does reproduce the observed response pattern to El Niño and La Niña. During the El Niño events, the subtropical jet streams in both hemispheres are intensified and displaced equatorward, and there is a tendency towards weak upper easterlies over the equator. The Southern Oscillation is a very stable feature of the integrations and is accurately reproduced in all experiments. The inter-annual variability at middle- and high-latitudes, on the other hand, is strongly dominated by chaotic dynamics, and the tropical SST forcing only modulates the atmospheric circulation. The potential predictability of the model is investigated for six different regions. Signal to noise ratio is large in most parts of the tropical belt, of medium strength in the western hemisphere and generally small over the European area. The ENSO signal is most pronounced during the boreal spring. A particularly strong signal in the precipitation field in the extratropics during spring can be found over the southern United States. Western Canada is normally warmer during the warm ENSO phase, while northern Europe is warmer than normal during the ENSO cold phase. The reason is advection of warm air due to a more intense Pacific low than normal during the warm ENSO phase and a more intense Icelandic low than normal during the cold ENSO phase, respectively.
\end{abstract}

\section{Introduction}

Knowledge of the atmospheric response to the El Niño phenomenon has gradually evolved during the last decade or so, although the phenomenon as such, the Southern Oscillation, was first reported as early as in the end of the last century (Hildebrandsson 1897). However, the Southern Oscillation has mainly been attributed to Sir Gilbert Walker who studied the phenomenon extensively in the 1920s and 1930s and gave it its present name (Walker 1924, 1925, 1928). The important relationship between the Southern Oscillation and the sea surface variations in the tropical Pacific was not discovered until the 1960s in studies by Ichiye and Petersen (1963), Berlage (1966) and Doberitz (1968). For a more in-depth background, the reader is referred to the excellent monograph by Philander (1989).

The Southern Oscillation is normally expressed as the correlation of the sea surface pressure between Darwin and Tahiti, while the typical structure, as can be seen from Fig. 1, taken from Trenberth and Shea (1987), shows a very large-scale correlation pattern. It suggests that the atmospheric impact of the sea surface temperature anomalies (SSTs) in the tropical Pacific are global in domain.

A general review of the anticipated climate impact of ENSO can be found in Glanz et al. (1991). Ropelewski and Halpert (1987) show anomalies in temperature and precipitation during the boreal winter, for episodes of warm SSTs anomalies in the tropical Pacific. They reinforce the impression of a worldwide effect on the weather systems.

It must be pointed out, though, that a causative relationship between a particular SST forcing and a climate response cannot be determined from empirical alone. The observed features could be concurrent by chance, or be due to other forcing factors. A series of numerical experimentations, differing only in their initial conditions, and systematically compared with experiments without the actual SST anomalies, can provide an important support for the empirical findings. 


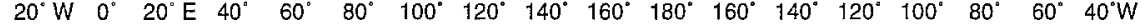

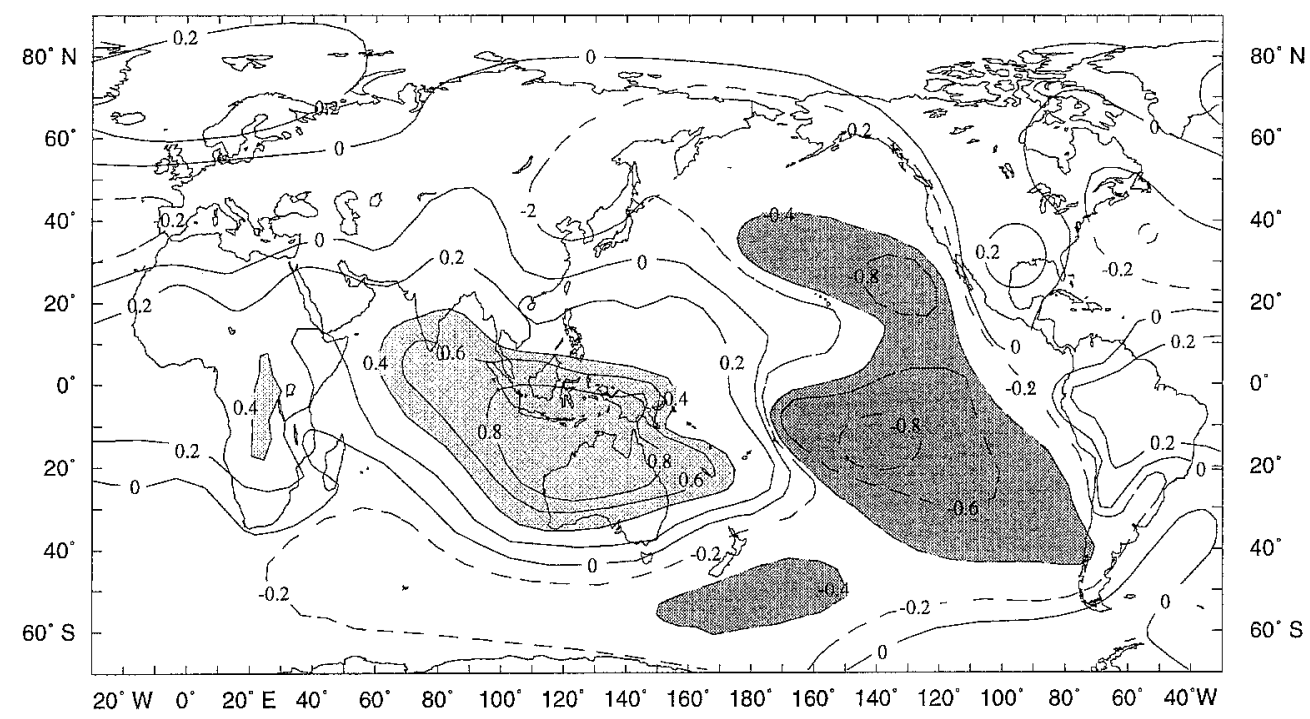

Fig. 1. Correlation of annual mean sea level pressure with the pressure at Darwin. Correlations exceed 0.4 in the shaded regions and are less than -0.4 in the regions with dashed lines (from Trenberth and Shea 1987)
Furthermore, such experiments can provide useful insight into the fundamental physical processes at work, and set an upper bound for the predictability of the phenomena.

Several numerical response studies to evaluate the overall effect of SST anomalies have been undertaken over the last ten years, e.g. Lau (1985), Kang and Lau (1987), which have demonstrated clearly the significance of tropical SST anomalies for the atmospheric tropical variability. The typical relationship between the surface pressure of Darwin and Easter Island representing the Southern Oscillation for the period 19621976 was well reproduced in the study by Lau (1985). At the same-time it was found that SST anomalies did not contribute in any significant way to the middleand high-latitude variance, although a contribution to the Pacific-North Atlantic, PNA pattern by some $20 \%$ was noticeable.

In view of the success in predicting the SST anomalies related to El Niño in recent years (e.g. Cane 1992), efforts are under way to develop comprehensive coupled ocean-atmosphere forecasting systems. Alternatively, special hybrid systems are also under evaluation. Here the SST pattern is calculated independently by a simplified coupled anomaly model. The time evolution of the SST anomaly pattern produced in this way is then added to the climatological SST pattern, which in turn is used to drive an atmospheric GCM. This approach has been successively tested and reported by Bengtsson et al. (1993) and Barnett et al. (1994).

An obvious issue to explore in the context of an operational implementation of an ENSO-type forecasting system is to address the following basic questions:

1. What is the atmospheric response to a given SST anomaly?

2. How does the response depend on the geographic position of the anomaly?

3. How stable is the atmospheric response (signal/ noise) to ENSO and what is the geographical distribution of the signal/noise pattern?
4. How does the stability of the signal depend on the phase of ENSO?

5. How does the strength and the stability of the ENSO signal depend on the season?

6. What modelling strategy would be reasonable to pursue for routine ENSO prediction?

The final answer to these questions must naturally await a proper operational evaluation, in order to be determined adequately. However, a tentative answer could be obtained by numerical experimentation along similar lines as has been done previously, e.g. by Lau (1985), more recently by Hoerling et al. (1992), and Ponater et al. (1994). We will undertake such a study with a present state-of-the-art model and integrated with higher horizontal and vertical resolution than before. An ensemble of five cases will be considered.

The study was done in the following way. A 14-year SST dataset from 1979 through 1992 was used. For the period 1979-1988, the AMIP data set was used (Gates 1992), thereafter SST data from NMC/CAC (Reynolds 1988). Five 14-year climate simulation calculations were carried out with the MPI ECHAM3 model, Roeckner et al. (1992), all starting from different atmospheric initial states.

We believe that it is important to undertake evaluation studies of this type from time to time, as new and more realistic models become available. Cubasch (1985), and Hoerling et al. (1992), have suggested that the atmospheric response to SST anomalies is strongly model dependent, in particular with respect to the handling of the parameterization of deep convection, radiation and boundary layer processes. Palmer and Mansfield (1986), found such dependence also on the handling of sub-grid scale orography.

The period 1979-1992 is a suitable test period, since it incorporates three fully developed El Niño (warm phase) and three La Niña (cold phase) of which the 1988/89 event was the strongest one. We will estimate an upper bound on predictive skill in selected areas and for different parts of the year, by evaluating the 
internal variability, expressed by the differences between the five realizations, and the mean seasonal variance. We will further try to combine the three warm and the three cold events, respectively, into a coherent picture of a characteristic global response pattern and its associated predictive stability. As far as possible we try to compare the model results with observational data. To validate the free atmosphere we use ECMWF analysis data which consist of re-analysis data for the period 1979-1984 and of operational analysis thereafter to 1993. To validate precipitation we use monthly mean analysis data from Schemm et al. (1992), Rudolf et al. (1992), and Janowiak and Arkin (1991); the former two are based on operational ground observations and the latter one is based on infra-red radiation observations from satellites.

The study is organized as follows. In Sect. 2, we provide a short summary of the ECHAM3 model with the emphasis on processes which we believe are of relevance to ENSO prediction, and in Sect. 3 we describe the design of the experiment. In Sect. 4 we discuss the general atmosperic response pattern to SST anomalies, and in Sect. 5 we assess the regional potential predictability for different seasons and during the different phases of ENSO.

\section{Description of the model}

The present study has been undertaken with the ECHAM3 model (Roeckner et al., 1992). ECHAM3 is the third generation GCM used for global climate modelling investigations in Germany. It is a spectral transform model with triangular truncation. It has evolved from the medium-range forecasting model used at ECMWF, but significantly modified to make it suitable for climate prediction. This investigation has been undertaken with a medium resolution version of the model at wave number T42. The main aspects of ECHAM3 are summarized in Table 1.

The parametrization of sub-grid scale processes is formulated in a simplified parametric form, partly because of insufficient detailed knowledge (e.g. the turbulent transfer and cloud micro-physics), and partly because a more accurate treatment would exceed presently available computer resources (e.g. the computation of radiative transfer). The radiation scheme uses a broad-band formulation of the radiative transfer equations with six spectral intervals in the infrared and four intervals in the solar part of the spectrum (Hense et al. 1982; Rockel et al. 1991). Gaseous absorption due to water vapour, carbon dioxide and ozone are taken into account as well as scattering and absorption due to aerosols and clouds. The cloud optical properties are parametrized in terms of cloud water content, which is an explicit variable of the model.

The vertical turbulent transfer of momentum, heat, water vapour and cloud water is based upon MoninObukhov similarity theory for the surface layer and the eddy diffusivity approach above the surface layer, as in the original ECMWF model (Louis 1979). The drag
Table 1. The ECHAM3 model

The ECHAM34 model

\begin{tabular}{ll}
\hline Forecast variables & $\begin{array}{l}\zeta, \mathrm{D}, \mathrm{T}_{\mathrm{W}}, \mathrm{q}, \ln \left(\mathrm{p}_{\mathrm{s}}\right), \mathrm{m} \text { (cloud wa- } \\
\text { ter) }\end{array}$ \\
Vertical representation & $\begin{array}{l}\text { Hybrid coordinate system }(\sigma \rightarrow \mathrm{p} \\
\text { with increasing height), } 19 \text { levels } \\
\text { (highest level } 10 \mathrm{hPa})\end{array}$ \\
Horizontal representation & $\begin{array}{l}\text { Spectral, with triangular truncation } \\
\text { at wave number } 42 . \text { Non-linear and } \\
\text { diabatic terms are calculated on a } \\
\text { Gaussian grid (2.8 lat/long) }\end{array}$
\end{tabular}

Time integration

Semi-implicit. Leapfrog with time filter (Asselin 1972) $\Delta \mathrm{t}=24 \mathrm{~min}$

Orography

mean

Radiation

Surface albedo

Horizontal diffusion

Vertical diffusion

Two stream approximation. Absorbers are $\mathrm{CO}_{2}, \mathrm{O}_{3}$, aerosols (prescribed) and water vapour, cloud water content (predicted). 4 solar and 6 terrestrial intervals. Annual and daily cycle (Hense et al. 1982; Rockel et al. 1991)

Climatological, but dependent on snow

Scale dependent (Laursen and Eliasen 1989)

At the surface: similarity principle corrections for weak winds (Miller et al. 1992)

Ekman layer and free atmosphere: dependent on Richardson number modified by moisture (Brinkop 1992)

Mountain drag

Gravity wave drag (Miller et al. 1989)

Convection

Mass flux scheme (Tiedtke 1989)

Cloud and precipitation

Prognostic equation for cloud water (Roeckner et al. 1991)

Surface processes

5-level heat diffusion scheme, one layer infiltration/runoff scheme (Dümenil and Todini 1992)

Sea surface temperature Climatology, averaged 1979-1988, or 1979-1988 AMIP SST and 19891992 (Reynolds 1988)

and heat transfer coefficients depend on roughness length and Richardson number, and the eddy diffusion coefficients depend on wind stress, mixing length and Richardson number, which has been reformulated in terms of cloud-conservative variables (Brinkop 1991, 1992).

The effect of orographically excited gravity waves on the momentum budget is parametrized on the basis of linear theory and dimensional considerations (Palmer et al. 1986; Miller et al. 1989). The vertical structure of the momentum flux induced by the gravity waves is calculated from a local Richardson number, which describes the onset of turbulence due to convective instability and the breakdown approaching a critical level. 
The parametrization of cumulus convection is based on the concept of mass flux and comprises the effect of deep, shallow and mid-level convection on the budget of heat, water vapour and momentum (Tiedtke 1989). Cumulus clouds are represented by a bulk model including the effect of entrainment and detrainment on the updraft and downdraft convective mass fluxes. Mixing due to shallow stratocumulus convection is considered as a vertical diffusion process with the eddy diffusion coefficients depending on the cloud water content, cloud fraction and the gradient of relative humidity at the top of the cloud.

Stratiform clouds are predicted per se in accordance with a cloud water equation including sources and sinks due to condensation/evaporation and precipitation formation both by coalescence of cloud droplets and sedimentation of ice crystals (Sundqvist 1978; Roeckner et al. 1991). Sub-grid scale condensation and cloud formation is taken into account by specifying appropriate thresholds of relative humidity depending on height and static stability.

The land surface model considers the budget of heat and water in the soil, snow over land and the heat budget of permanent land and sea ice (Dümenil and Todini 1992). The heat transfer equation is solved in a fivelayer model assuming vanishing heat flux at the bottom. Vegetation effects such as interception of rain and snow in the canopy and the stomatal control of evapotranspiration are grossly simplified. For a more extensive report, reference is made to Roeckner et al. (1992), Arpe et al. (1994a), May and Bengtsson (1994) and Bengtsson (1994b).

\section{The design of the experiment}

The purpose of the experiment was to evaluate the long term atmospheric response to prescribed SST anomaly patterns over the period $1979-1992$ by carrying out a series of simulations with the same atmospheric model but starting from different atmospheric initial states.

The ECHAM3 model was essentially finalized in late 1992 and has since then been extensively used in different climate experiments. Together with a large number of other modelling groups, the ECHAM3 model has also taken part in AMIP investigations (Gates 1992). The model has mainly been used at low and medium horizontal resolutions, T21 and T42, in addition shorter integrations of 5 years duration have been done at a T106 resolution (Bengtsson et al. 1994; Arpe et al. 1994a). In this study we only address such aspects of the performance of the model which are of relevance here.

Five different integrations were carried out all using different atmospheric initial states. The initial data were all obtained from control runs with climatological SST starting several months beforehand. The original archive was generated with a time resolution of 12 hours; the majority of the investigations in this study has been using a special archive of seasonally averaged data.

The central objective of this study is to explore the impact and importance of SST anomalies on the low frequency circulation of the atmosphere. For intercomparison, we have also undertaken a series of 30 year control integrations, using instead a climate monthly mean state of the sea surface temperature. The SSTs in the control experiments are averages for the years 1979-1988.

\section{The general atmospheric response pattern to SST anomalies}

It is hardly possible to identify the causes of the observed variability by empirical studies only. This would only be possible if, for example, we had a situation where the SST patterns repeated themselves in a regular manner over a suitable period of time. However, this is not case, and even a well-described phenomenon like El Niño differs quite a lot both in amplitude and in structure from one time to another, e.g. Berlage (1957). Furthermore, other ocean regions may have SST anomalies which do not coincide with El Niño and hence every situation is a new one. A deeper understanding as to the possible effect of SST anomalies on the circulation of the atmosphere and thus of climate variations can be arrived at by means of systematic numerical experimentation, incorporating the global SST pattern.

As we will see, the problem of identifying the effect of SST on climate fluctuations is particularly difficult at middle- and high-latitudes, where the dynamical instability of the westerlies contributes to a very complex, chaotic circulation. The causes of a particular flow configuration are in many ways virtually meaningless to try to identify, since a particular pattern can be generated by a multitude of different forcing mechanisms. Our science has regrettably been beset by fruitless attempts to "explain" a particular circulation pattern and relate it to a specific and simple cause!

Figure 2 shows the interannual variability of seasonal mean $500 \mathrm{hPa}$ geopotential heighs during the boreal winter for the simulations using climatological SST and observed SST, respectively, as well as for analysis data. The variance at middle- and high-latitudes is essentially the same in all three panels, while in the tropics the variance for the simulations using climatological SST is essentially halved. The variance of other basic parameters, such as surface pressure and vorticity and temperature throughout the troposphere, show a similar picture.

The difference in the response to boundary forcing at low and high latitudes can effectively be illustrated by Fig. 3, which shows the variation of the $700 \mathrm{hPa}$ temperature (anomalies) with longitude for two latitudinal belts, $40^{\circ}-50^{\circ} \mathrm{N}$ and $10^{\circ} \mathrm{S}-10^{\circ} \mathrm{N}$ for the five simulations for the winter 1982/83 at the peak of the extraordinary 1982/83 El Niño. As can be seen, there are considerable variations between the different members 

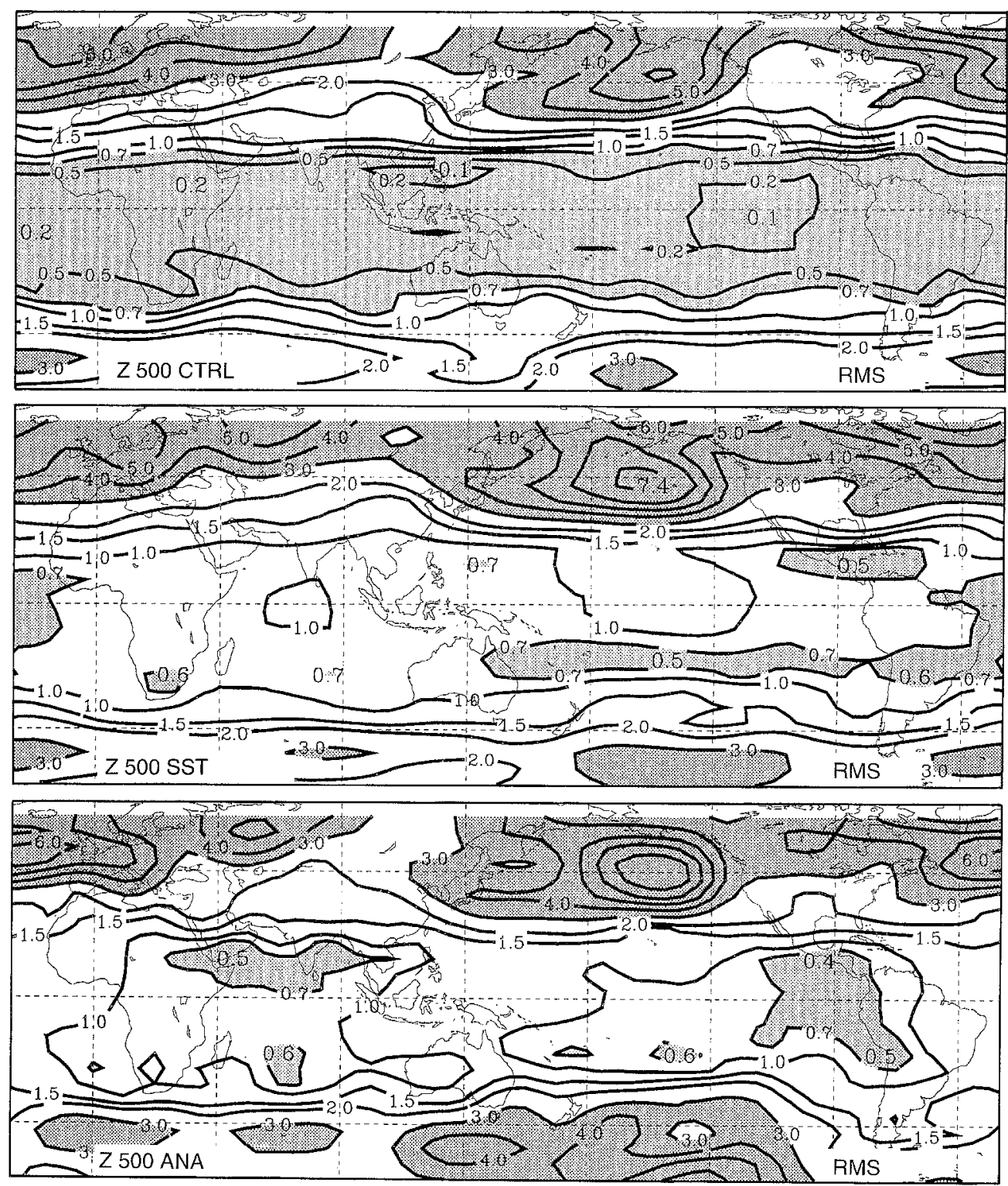

Fig. 2. RMS variability of the boreal winter mean $500 \mathrm{hPa}$ geopotential. Upper panel shows the simulation based on climatological SST, middle pan el the simulation based on observed SST and the lower panel the analysis data. Units in decametres of the ensemble in the extra-tropics, representing quite different weather conditions, in particular over western Europe. Over the western United States all realizations show a trend towards positive anomalies. For the tropics only very small deviations from the ensemble means at all longitude are found. An increase of midtropospheric temperatures during $\mathrm{El}$ Niño in the tropics is obvious, especially over the Pacific as might be expected but also over Africa. This demonstrates the quasi-linear response to the boundary conditions in the tropics as well a complex chaotic behaviour in middleand higher latitudes.

Figure 4 depicts the variation of the zonal wind in a latitude-time diagram averaged for the band $125^{\circ}-$ $100^{\circ} \mathrm{W}$ during MAM (March - April - May). We have chosen the season MAM because it gives the clearest signal as already found by Brankovic et al. (1994). The mean of the five simulations is compared with the analysis data. The single simulations are very similar to their mean which is demonstrated in Fig. 5 for 1983 and 1988 , so this response is apparently a stable feature of the model as well as of the real atmosphere. During the El Niño events, the subtropical jet stream in the Northern Hemisphere is intensified, and the westerlies over the equator are weakened, even turning to easterlies. Simulations and analyses show similar anomalies. A strengthening of the Hadley circulation can be inferred. A similar tendency occurs also during the boreal winter but then the effect is mainly confined to the Northern Hemisphere. According to Philander (1989), and in agreement with our findings here, this is actually what is observed in a mature El Niño event. During La Niña events there is a weakening of the subtropical jet stream in the Northern Hemisphere and a strengthening of the westerlies at the equator. The simulations show also an unrealistic northward shift of the subtropical jet. During La Niña events the simulations agree less well with observations than during El Niño events. The Southern Hemisphere jet shows a strong change in position between cold and warm events, which is very 

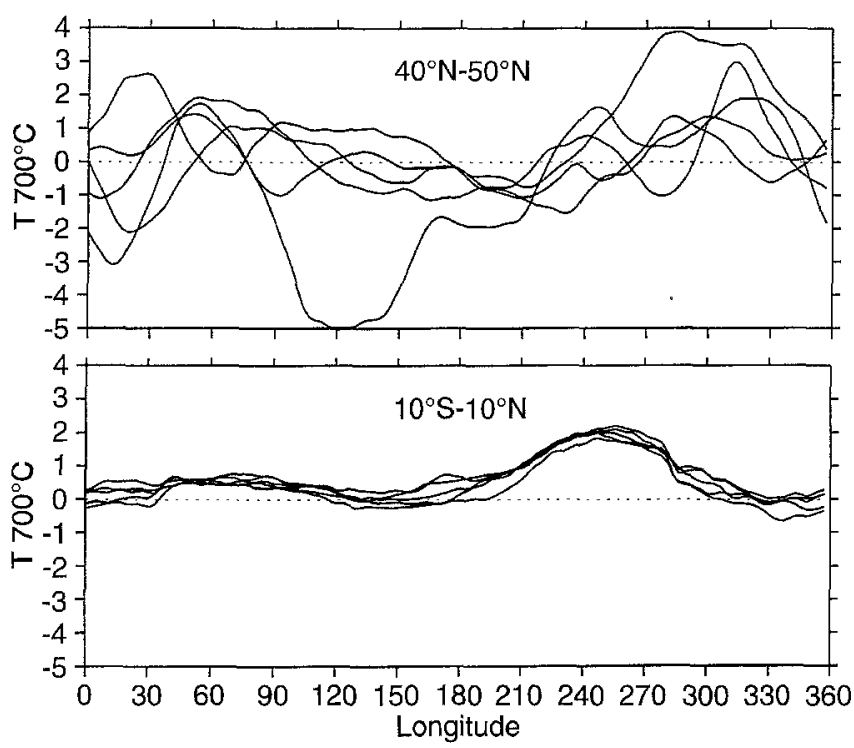

Fig. 3. Five different realizations of the anomalies of the $700 \mathrm{hPa}$ temperature between $40^{\circ}$ and $50^{\circ} \mathrm{N}$ (upper panel) and between $10^{\circ} \mathrm{S}$ and $10^{\circ} \mathrm{N}$ (lower panel) for DJF 1982/83. All simulations are based on observed SST data, but from different atmospheric initial states

clear in the simulation and indicated as well in the analysis.

We next address the questions whether certain aspects of the circulation, such as the frequency of blocking, may be more common under certain SST patterns than in others, whether there will be certain changes in the storm tracks, or whether certain Grosswetterlagen will dominate under one set of SST pattern and not in another. A detailed evaluation of the experiments with ECHAM3, e.g. May and Bengtsson (1994), shows that it is very difficult indeed to find any such simple response pattern, and that the frequency of blocking is
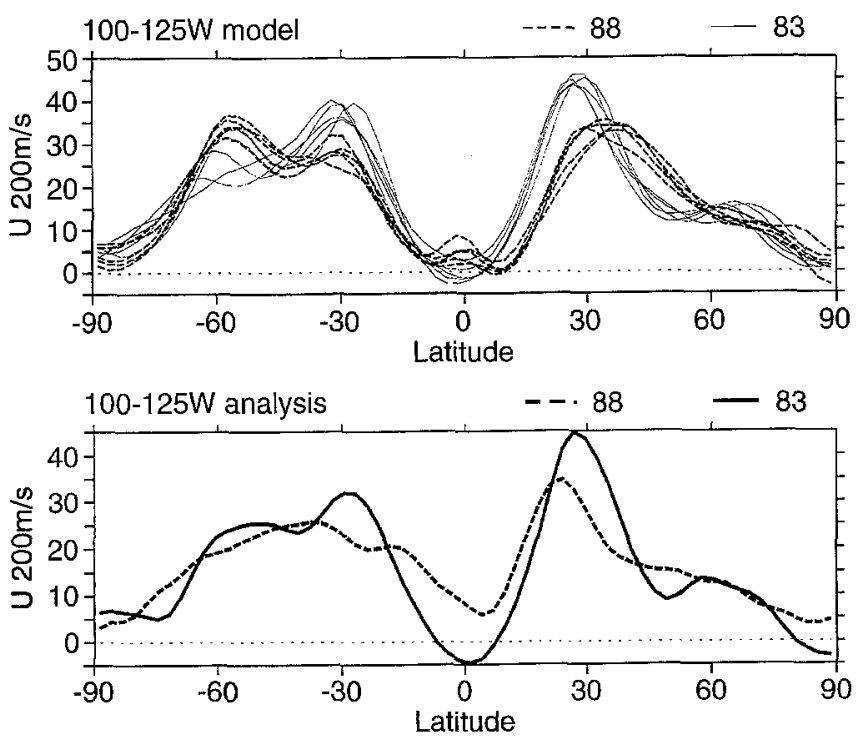

Fig. 5. The $200 \mathrm{hPa}$ zonal wind between $125^{\circ} \mathrm{W}$ and $100^{\circ} \mathrm{W}$ during the boreal spring. Top, individual simulations for the 1983 warm event (solid lines) and for the 1988 cold event (dashed lines); bottom, the same but for analysis data
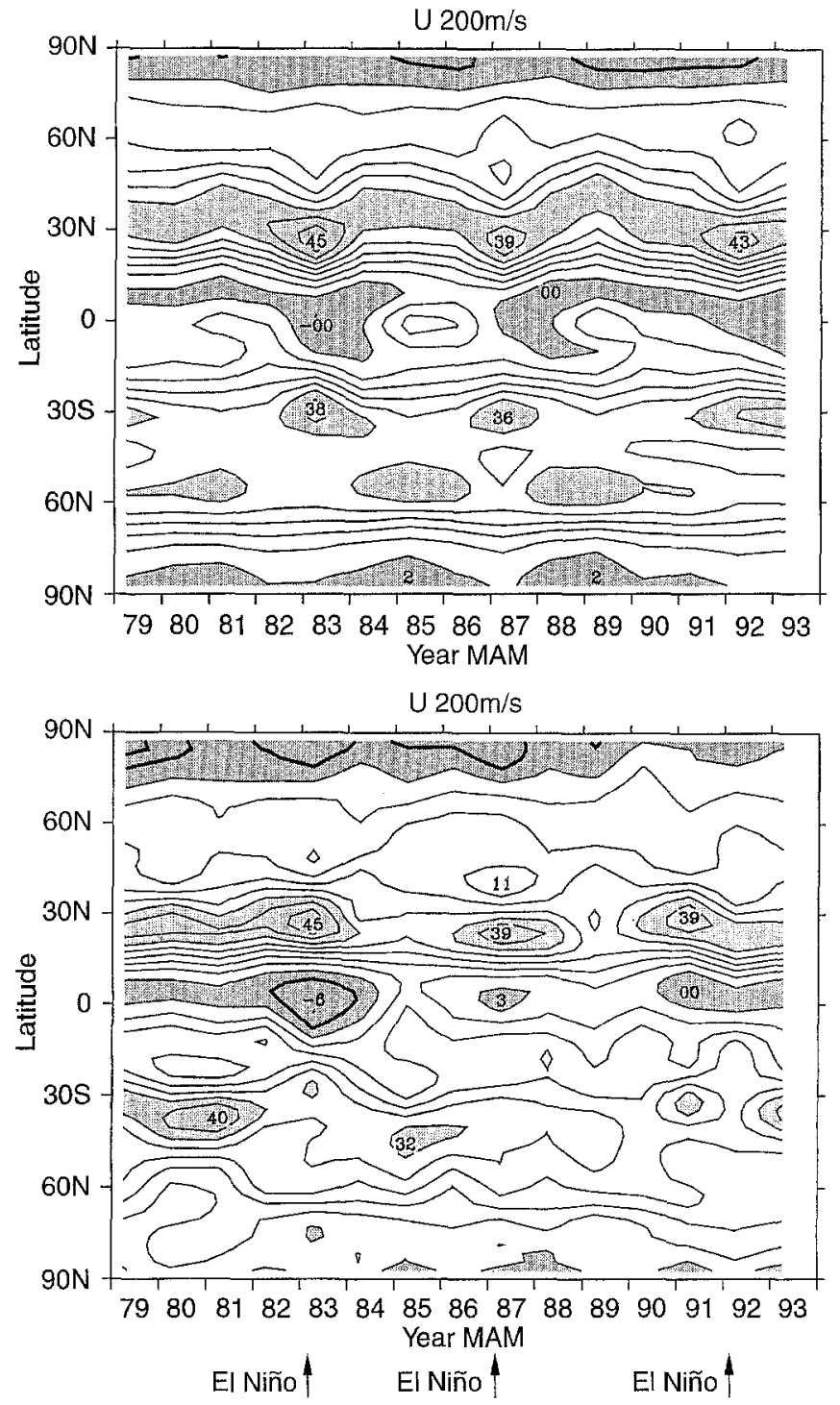

Fig. 4. The $200 \mathrm{hPa}$ zonal wind averaged in the band $125^{\circ}$ to $100^{\circ} \mathrm{W}$ during the boreal spring. upper panel, mean of five simulations; lower panel, analysis. Westerly winds stronger than $30 \mathrm{~m} \mathrm{~s}^{-1}$ are heavily shaded and winds weaker than $5 \mathrm{~m} \mathrm{~s}^{-1}$ are lightly shaded. The peaks of the El Niño events are marked

virtually the same in two sets of runs (climate SST or observed SST), suggesting that atmospheric blocking is independent of SST anomalies.

We study this question by comparing two sets of one point correlation maps for the mean sea level pressure using the reference "point" $\left(40^{\circ}-45^{\circ} \mathrm{N} ; 165^{\circ}-\right.$ $175^{\circ} \mathrm{W}$ ) to represent the Aleutian centre of action, and the "point" $\left(55^{\circ}-60^{\circ} \mathrm{N} ; 35^{\circ}-45^{\circ} \mathrm{W}\right)$ for the Icelandic centre of action. Figure 6 shows the correlation patterns for these two centres of action for DJF (December - January - February) in the analysis data and in the experiment with observed SST $(5 \cdot 14$ years $)$ and climate SST (30 years) respectively. The patterns for the same centre of action are remarkably similar. The characteristic negative correlation between the two centres of action is also easily seen, confirming the empirical finding of the alternating intensity between the Icelandic and Aleutian low. 

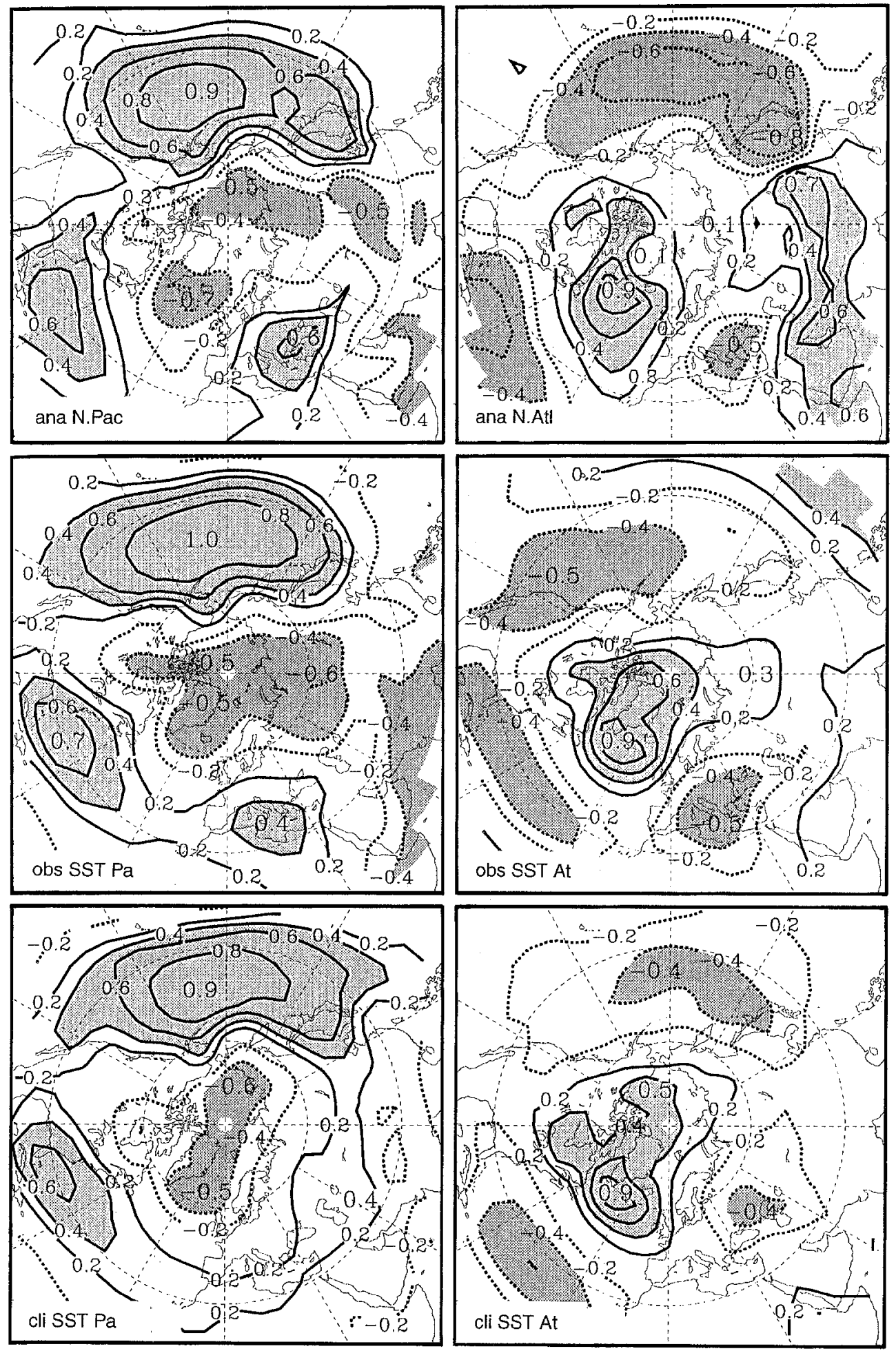

Fig. 6. Correlation of mean sea level pressure during winter between the North Pacific centre of action $\left(40^{\circ}\right.$ to $45^{\circ} \mathrm{N} ; 165^{\circ}$ to $175^{\circ} \mathrm{W}$ ) and the North Atlantic centre of action $\left(55^{\circ}\right.$ to $60^{\circ} \mathrm{N}$; $35^{\circ}$ to $\left.45^{\circ} \mathrm{W}\right)$. Upper panels, analysis; middle panels, simulations based on observed SST; and lower panels, based on climatological SST
We have also calculated the corresponding correlation maps for precipitation and for surface temperature. They are consistent with the pressure anomaly, showing for example a negative correlation between the Icelandic pressure and the temperature over Western Europe. From these correlation maps we conclude that these patterns represent an atmospheric mode which is not dependent on variable SST.

However, when looking into time series of seasonal averaged surface pressure of the Aleutian centre of action $\left(40^{\circ}-45^{\circ} \mathrm{N} ; 165^{\circ}-175^{\circ} \mathrm{W}\right)$ in Fig. 7 , there is a strong signal from the ENSO events in the simulations with observed SST as well as in the analysis data. There are low Pacific values in the warm cases and high values during the cold cases. The variation in the Atlantic (Fig. 8) is reversed. We have inspected other seasons as well; the spring signal is very marked in the Pacific with hardly any variability for the warm events, while 

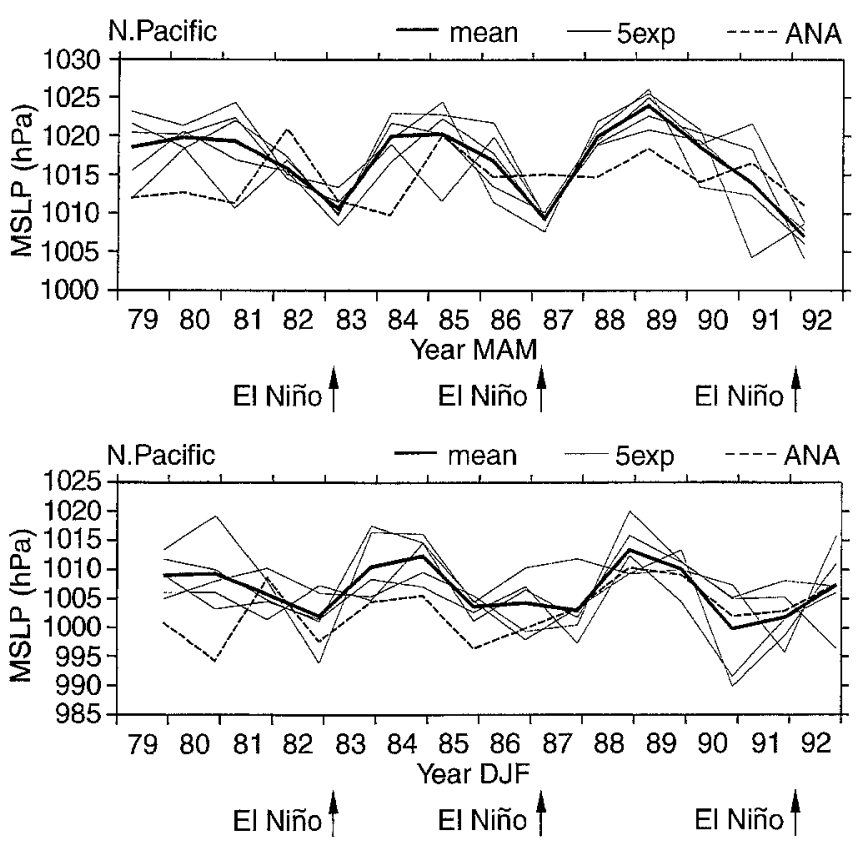

Fig. 7. Variation of mean sea level pressure over the North Pacific centre of action for the period 1979-1992. Top: Spring. Bottom: Winter. Note the modulation of the mean sea level pressure caused by the ENSO signal
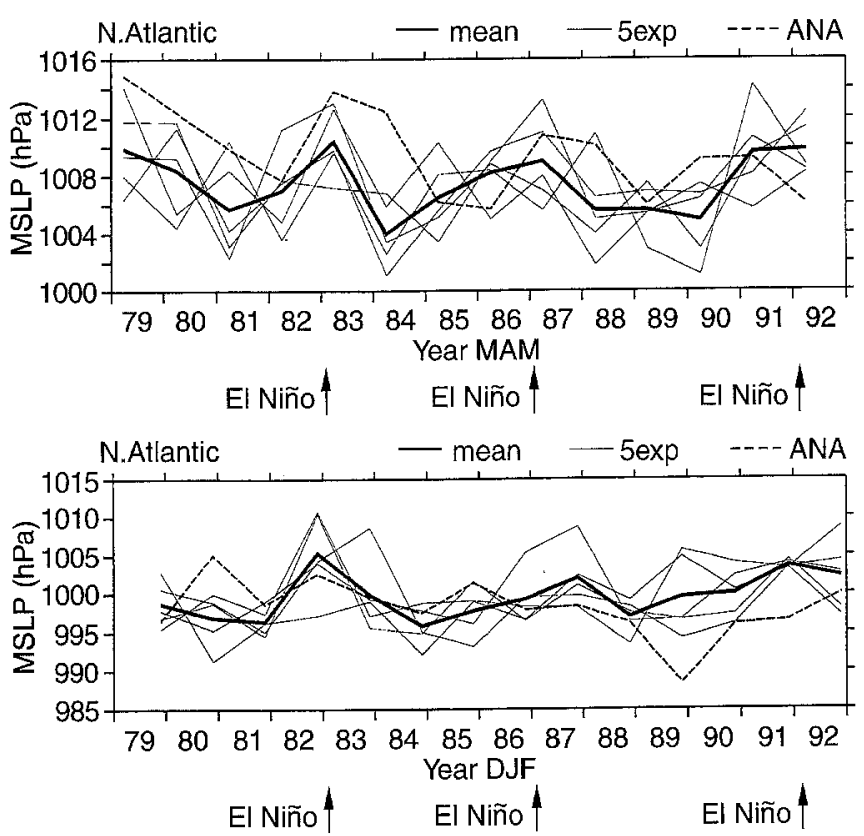

Fig. 8. The same as Fig. 7, but for the North Atlantic

in the Atlantic the variability is quite high. The amplitude of the ENSO signal is about twice as high in the Pacific centre of action as in the Atlantic one.

Similar time series from the simulations using climatological SST show variations of similar amplitudes as in Fig. 7 and 8 . The variability of the mean sea level pressure in the extra-tropics is therefore barely affected by SST anomalies in its amplitude, the SST being important only for the timing of anomalies.

\section{Assessment of regional predictability}

There is an indication that the SST anomaly has a typical eastward progression, and a periodic response of about 4 years could in fact be analyzed (M. Giorgetta, personal communication). Of particular interest is a study by Delecluse et al. (1994), whereby a mechanism for the propagation of the Pacific SST anomaly into the tropical Atlantic Ocean by means of a coupled ocean-atmosphere mode was suggested. A propagation into the Indian Ocean can in principle take place by means of a similar, ENSO induced, mechanism (Villwock 1994).

Figure 9 shows the composite El Niño and La Niña pattern during the period 1979-1992, as well as the temperature variability in the NINO 3 area during MAM of that period. Three warm and three cold events took place during the period, making it one of the most pronounced and regular series of events this century.

The usual way of presenting its atmospheric component, the Southern Oscillation, is to calculate the correlation of the annual mean sea level pressure with the pressure at Darwin. This has been done in Fig. 10, where we have brought together results using ECMWF analysis and simulations with observed and climatological SST. The empirical result from Trenberth and Shea (1987) shown in Fig. 1 agree very well with both
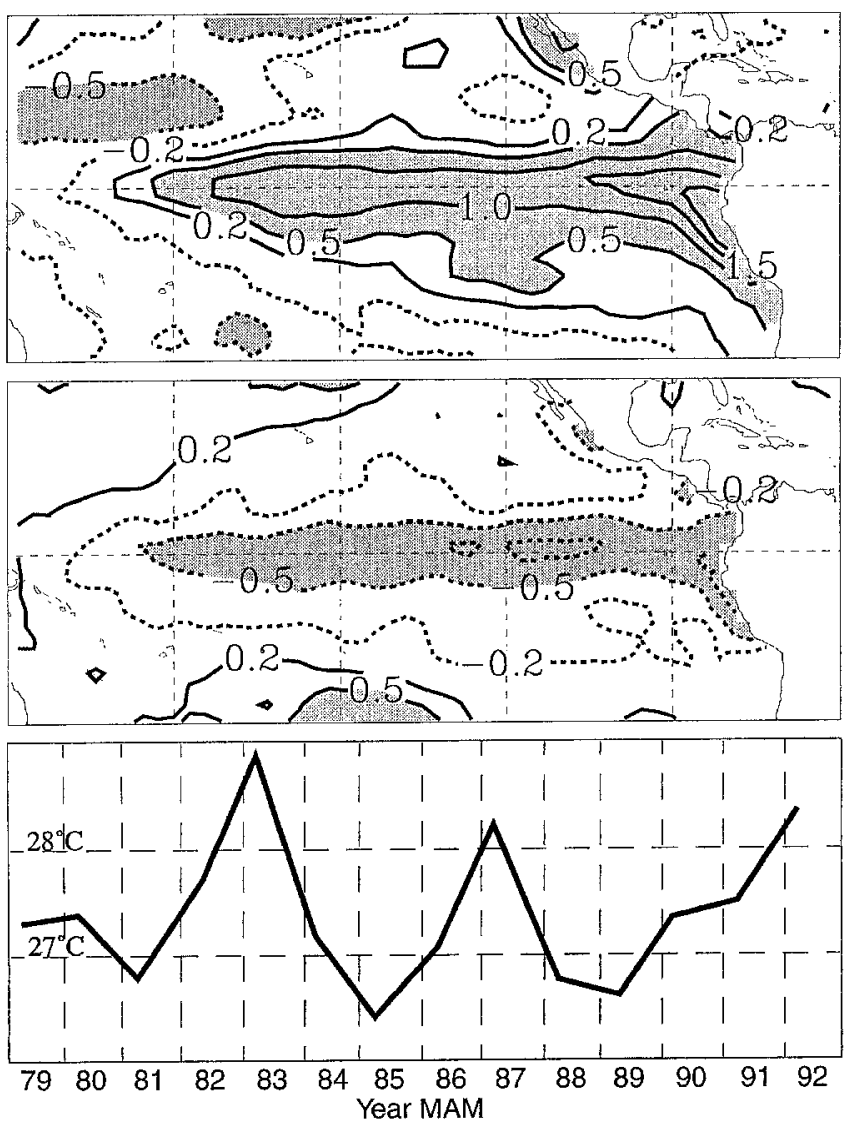

Fig. 9. The composite El Niño and La Niña anomaly patterns $\left({ }^{\circ} \mathrm{C}\right)$ and the associated temperature changes in the NINO3 area during MAM for the period 1979-1992 

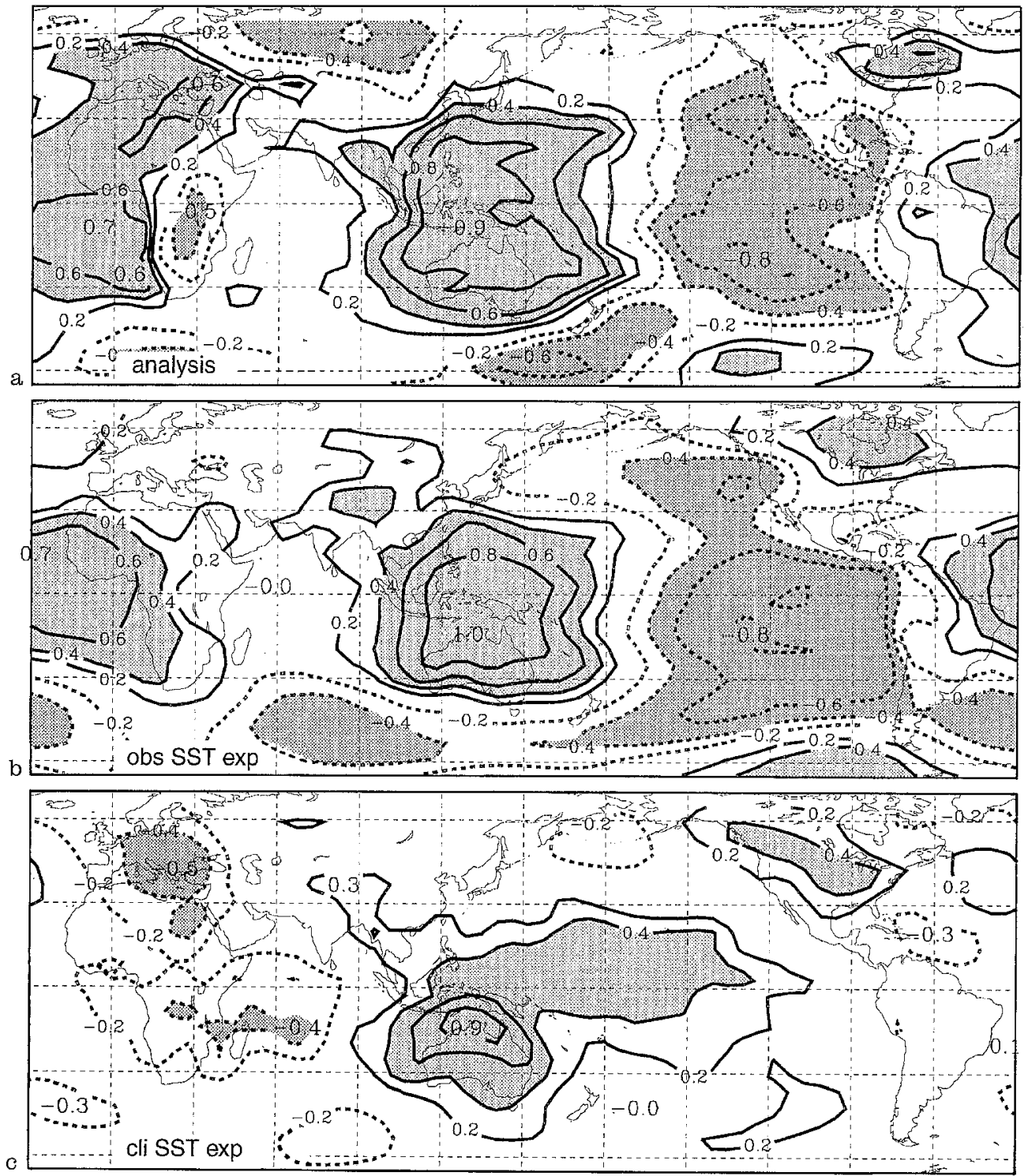

Fig. 10a-c. Southern Oscillation as calculated from a analysis; $\mathbf{b}$ simulated from the observed SST run and $\mathbf{c}$ simulated by the climate SST run. Correlations exceed 0.4 in the lightly shaded regions and are less than -0.4 in the heavily shaded regions the maps using analysis and using simulations with observed SST. In fact the map by Trenberth and Shea (1987) agrees more with the model results than with the map from ECMWF analyses, suggesting that a 15year ensemble may be too short for gaining a stable result. The calculations from the 30-year control experiment with climatological SST gives a completely different pattern, suggesting that the Southern Oscillation is forced by the SST. We have also explored the stability of the Southern Oscillation signal by comparing the Southern Oscillation correlation pattern from each of the five 14-year integrations. Although there are some minor differences at high latitudes, the patterns are virtually identical in the tropics. These results reinforce previous results (e.g. Lau 1985) and stresses the high reproducibility of the Southern Oscillation.

For each specific season we have correlated the SST, averaged for the NINO3 area, with different primary meteorological parameters such as mean sea level pressure, $500 \mathrm{hPa}$ geopotential, $850 \mathrm{hPa}$ temperature, precipitation and where available, snow depth. In addition we have also calculated the global SST corre- lation (not shown). We present here the correlation maps for the boreal winter and spring respectively.

Figure 11a shows the correlation field with mean sea level pressure for the boreal winter. A negative correlation pattern with values below -0.5 covers the major part of the eastern Pacific with one branch stretching into the Gulf of Mexico, while a positive correlation pattern with values higher than +0.5 covers the remaining part of the tropics almost completely. The highest positive correlation occurs over Indonesia and the south Atlantic Ocean west of Namibia. At high-latitudes the correlation is weaker, but values above +0.5 occur over the Labrador Sea. In many respects Fig. 11a resembles Fig.10b, stressing again the linkage between the Southern Oscillation and tropical Pacific SST.

The $500 \mathrm{hPa}$ geopotential pattern (Fig. 11b) extends over the whole tropical belt, with positive values above +0.7 essentially everywhere between $25^{\circ} \mathrm{S}$ and $15^{\circ} \mathrm{N}$. High negative correlations occur in a band poleward, with values below -0.5 over parts of the western hemisphere. Further northwards there is another band of 

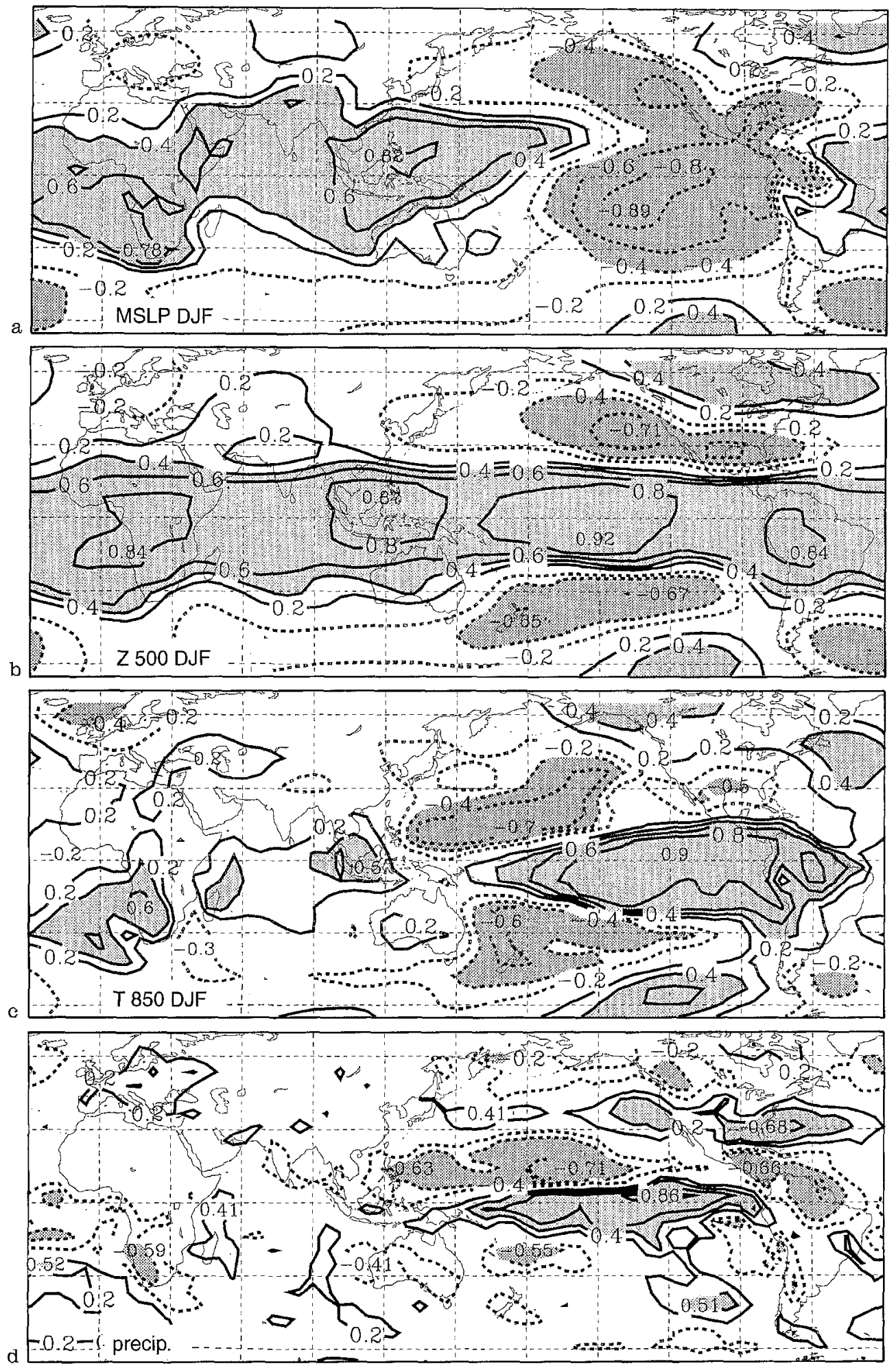

Fig. 11a-d. Correlation of the NINO3 SST with different meteorological parameters during boreal winter. a mean sea leve pressure; b $500 \mathrm{hPa}$ geopotential; c $850 \mathrm{hPa}$ temperature and d precipitation

high positive correlation. Values above +0.5 occur over parts of central and eastern Canada. During El Niño, a pattern like this is expected to strengthen the subtropical jet, particularly over the western hemisphere, and give it a more equatorward position. The opposite will happen during a La Niña event. This has been shown already in Fig. 4.

The $850 \mathrm{hPa}$ temperature (Fig. 11c) is dominated by the large positive correlation pattern over the major part of the tropical Pacific. A positive correlation can be found over western Canada and a weak negative correlation over northern Europe. We return to these areas in more detail later when we deal with the conditions during fully developed warm and cold events.

Precipitation is a key meteorological parameter, and changes in precipitation patterns during ENSO events are of principal concern to society, in particular since many dry and semi-dry areas are affected. The ENSO 

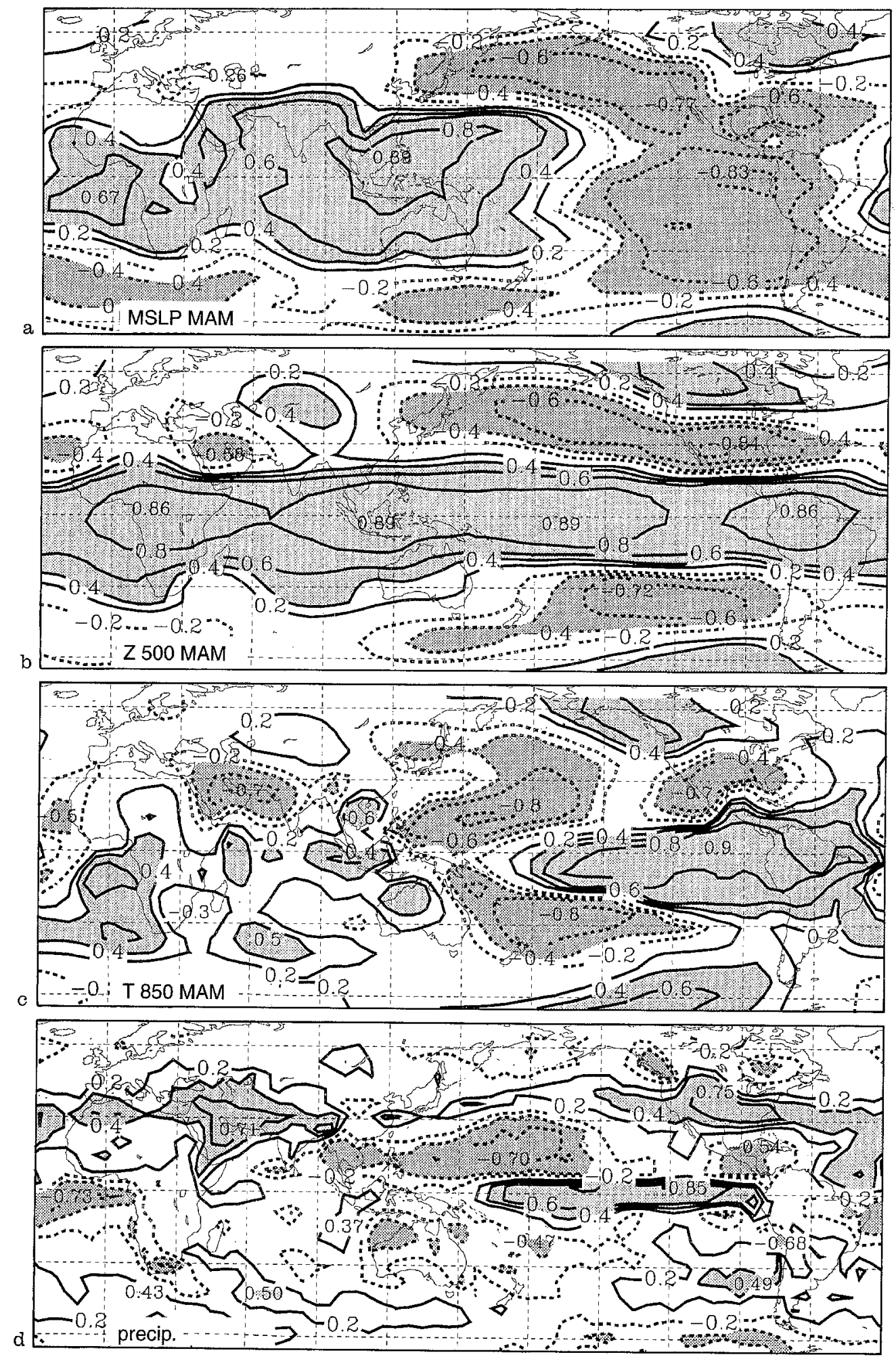

Fig. 12a-d. The same as Fig. 15, but for the boreal spring

events affect in a major way the large-scale circulation both in the equatorial plane and in the meridional plane. Over the tropical Pacific there is a direct and pronounced positive correlation of the SST anomaly, while a negative correlation occurs essentially over the major part of the tropical land areas, northern Brazil, Southern Africa and parts of Indonesia and Australia. The comparatively strong correlation over the southern United States is particularly interesting and in agreement with observational studies by Ropelewski and Halpert (1987); the main cause is probably the changes in the position and intensity of the tropical jet in the area and hence increased cyclone activity in the warm events, and decreased cyclonic activity in the cold events.

Figure 12 shows the same results as Fig. 11, but for the conditions during the boreal spring. The correlation patterns are very similar and in fact even more 
Table 2. Areas where the simulations are specifically evaluated. For further information see text

\begin{tabular}{lccl}
\hline Area & Latitude & Longitude & $\begin{array}{l}\text { Land } \\
\text { Ocean }\end{array}$ \\
\hline NINO3 & $4 \mathrm{~N}-4 \mathrm{~S}$ & $149 \mathrm{~W}-90 \mathrm{~W}$ & $\mathrm{O}$ \\
NE. Brazil & $10 \mathrm{~N}-4 \mathrm{~S}$ & $59 \mathrm{~W}-39 \mathrm{~W}$ & $\mathrm{~L}$ \\
Indian Peninsula & $21 \mathrm{~N}-10 \mathrm{~N}$ & $65 \mathrm{E}-90 \mathrm{E}$ & $\mathrm{L}$ \\
N. Australia & $21 \mathrm{~S}-15 \mathrm{~S}$ & $115 \mathrm{E}-155 \mathrm{E}$ & $\mathrm{L}$ \\
S. United States & $41 \mathrm{~N}-30 \mathrm{~N}$ & $104 \mathrm{~W}-97 \mathrm{~W}$ & $\mathrm{~L}$ \\
W. Canada & $69 \mathrm{~N}-46 \mathrm{~N}$ & $135 \mathrm{~W}-110 \mathrm{~W}$ & $\mathrm{~L}$ \\
\end{tabular}

pronounced than for the boreal winter, in agreement with findings by Brankovic et al. (1994). Also typical of the spring pattern is the area of positive correlation for precipitation over southwestern Asia with a centre over Iran and Iraq and another area of high correlation over Morocco and northern Algeria. Thus, indications are strong that it is during the boreal spring that we can expect to obtain the strongest ENSO signal. The reason for this is probably a combination of high SST amplitude during the boreal spring and a simultaneously existing meridional vorticity gradient which is essential for the poleward propagation of the ENSO signal.

A prerequisite for preditive skill is the ability to reproduce a signal. We study this by systematically investigating the five individual experiments. Instead of going through a standard statistical calculation, we have decided to evaluate the experiments in a more useroriented way. Furthermore, we will generally ignore areas where the correlation is very small and simply conclude that ENSO prediction is of limited value in such regions. However, we will return to this issue later, when we study the potential predictability in situations of extreme SST conditions.

For a more in-depth discussion we have selected 6 different areas defined in Table 2 and shown in Fig. 13. An example of an area with very high predictability of the meteorological conditions is the NINO3 area itself.
Figure 14 shows the simulation of precipitation for each season and for each of the five individual integrations. The heavy line is the mean value. It is clearly demonstrated that precipitation is directly coupled to the SST anomaly. The huge SST anomaly in 1982/83 generates excessive precipitation in the area, while precipitation during the 1986/87 and the 1991/92 warm events, for most seasons, is significantly smaller. The remarkably high reproducibility of the precipitation over the area is nevertheless reassuring and an indication of the very highly predictability of the atmospheric parameters during the event. Also the great similarity with analytical data give confidence that the precipitation in this area is predictable.

We next discuss the ENSO response and predictability for three tropical regions: northeast Brazil, the Indian subcontinent and northern Australia. For these areas we concentrate on the predictability of precipitation. Mean sea level pressure is an uninteresting parameter in the tropics and surface temperature varies essentially in an opposite way to precipitation, since low precipitation is associated with high temperatures and vice versa. Over northeast Brazil (Fig. 15) the precipitation varies in the opposite way to that of the NINO3 area, and reaches a minimum during the warm events and a maximum during the cold events. The signal is well reproduced for all seasons, although the model tends to underpredict the amounts of precipitation in all seasons except winter. During the spring the variations are small, in agreement with observations. A minimum in MAM 1990 in all experiments and in the analysis suggests that SST anomalies other than those in the tropical Pacific are important as well for this area.

The relationship between the ENSO and the Indian Monsoon has been a key scientific issue since the early papers by Walker (see also Rasmussen and Carpenter 1983 and Shukla and Mooley 1987). The general finding is that there is a weak negative correlation between a warm ENSO event and a strong monsoon and vice versa in the case of a cold event. Figure 16 summarizes

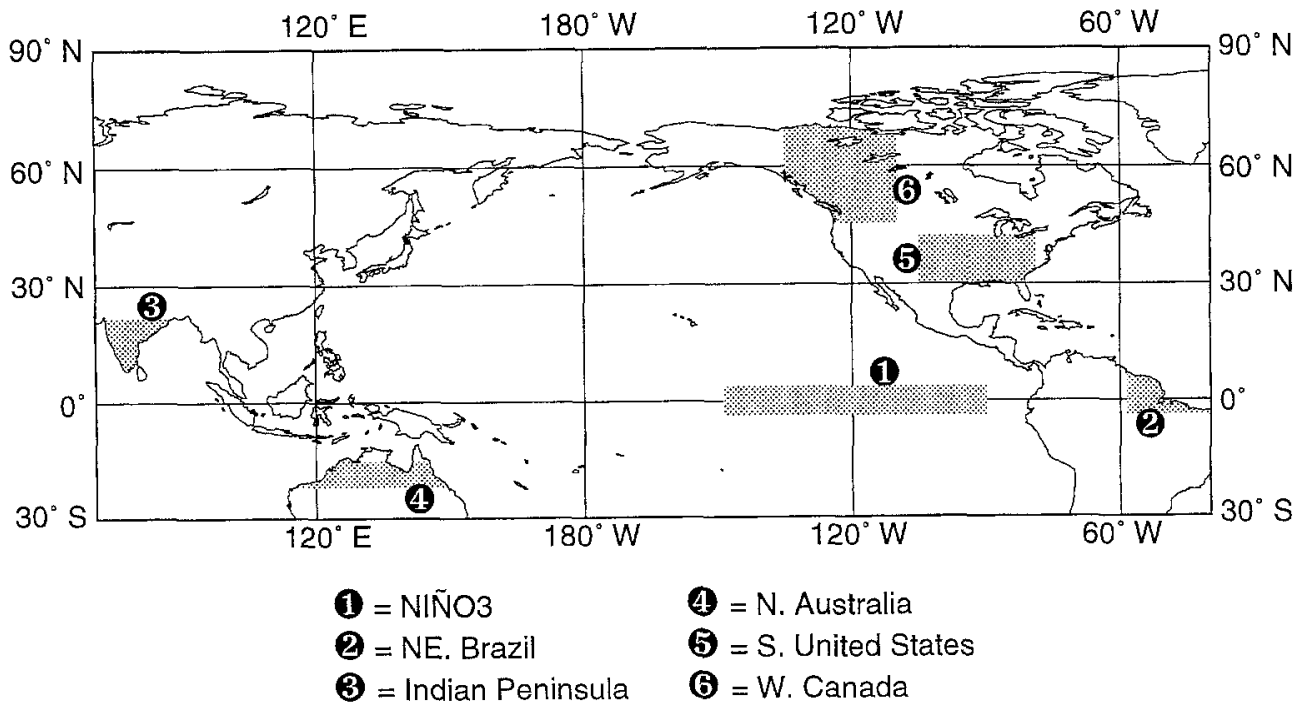

Fig. 13. Specially investigated areas as described in Table 2 

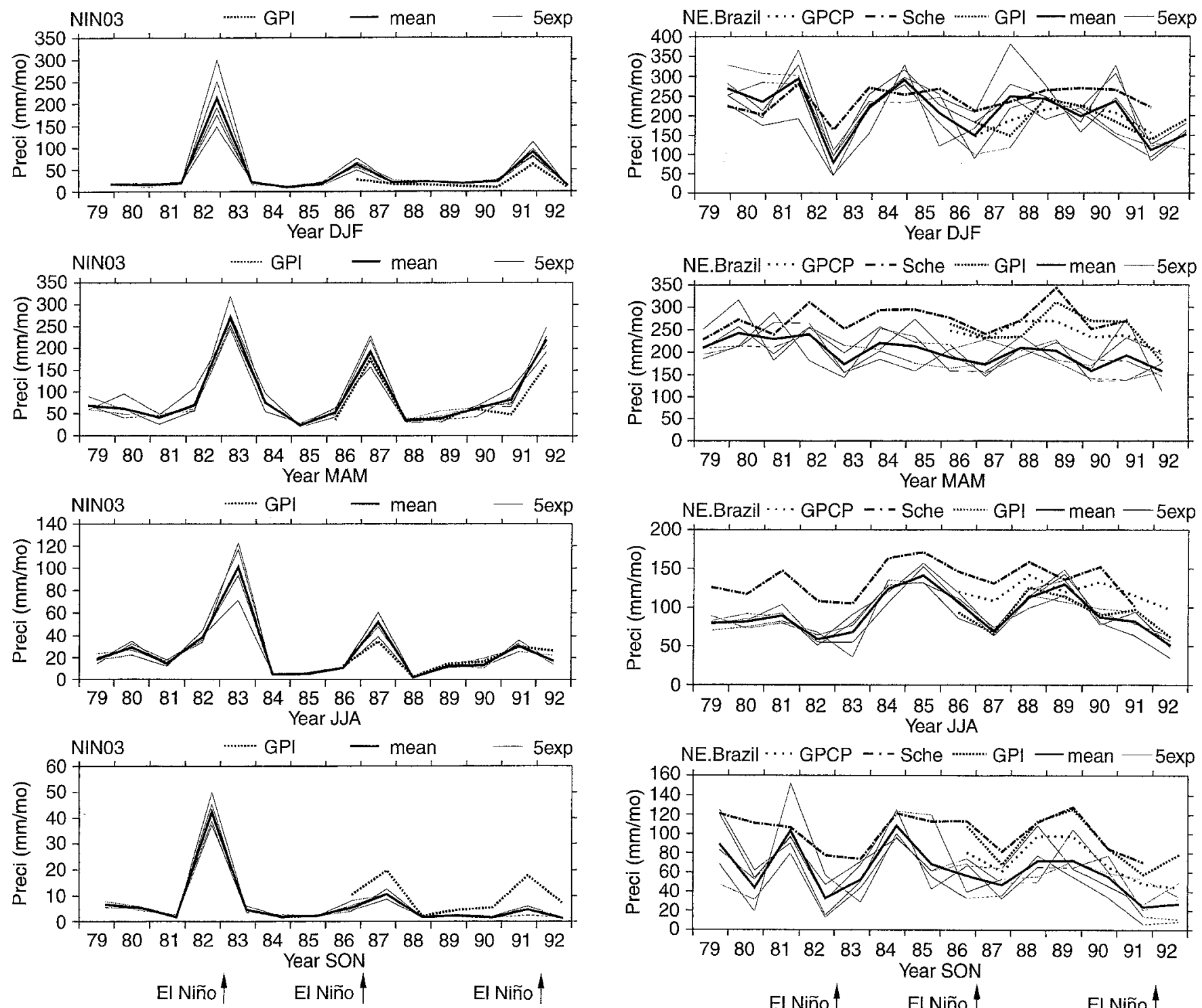

Fig. 14. Variation of precipitation in the NINO3 area separately for all four seasons. The thin curves indicate the individual experiments and the heavy line the average. GPI estimates shown by dotted lines are from Janowiak and Arkin (1991). El Niño events are marked

the precipitation for two seasons. During JJA the signal is rather weak and considerable variations exist between the five different cases. In this season the relation between the ENSO events and monsoon precipitation is particularily weak in the simulations as well as in the analyses. During SON the coherence between the different simulations is much larger and also the strong difference between 1987 and 1988 is realistically simulated. Arpe et al. (1994b) have analyzed the Indian precipitation variations and their possible causes, and have concluded that there are considerable chaotic variations in the area, presumably caused by instability features such as monsoon depressions. Other parameters like the mean surface pressure give a steadier signal with maxima during warm events and minima during cold events. From Fig. 16 an underprediction of precipitation during JJA, can be recognized and the argu-

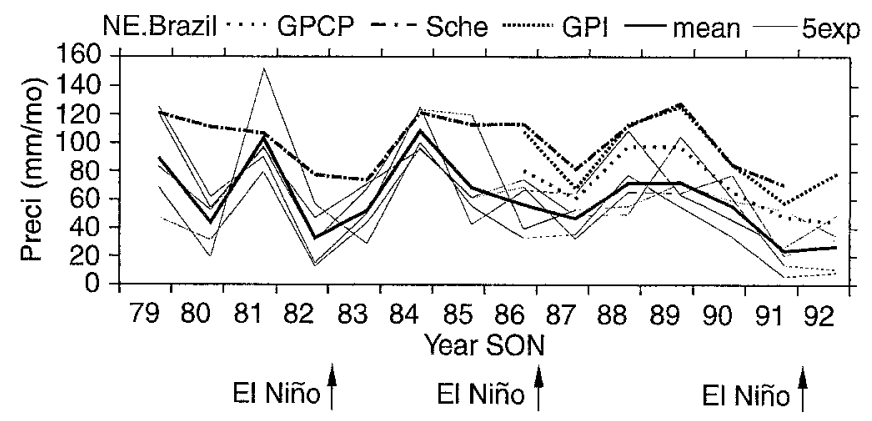

Fig. 15. The same as Fig. 14, but for northeast Brazil. GPCP is analysis by Rudolf et al. (1992) and Sche is analysis by Schemm et al. (1992)

ment by Palmer et al. (1993) that a realistic mean precipitation amount is a requisite for simulating the right interannual variability may be valid.

Precipitation over a large part of Australia reaches a minimum during the warm events and a maximum during the cold events (Ropelewski and Halpert 1987). Figure 17 shows the precipitation over northern Australia. Temperature and sea level pressure vary oppositely to precipitation. A clear signal like that found by Ropelewski and Halpert (1987) can be found during the austral autumn, at least in the simulations. During the austral summer the simulations show great coherence but the interannual variability is barely correlated with ENSO events. The analysis are neither correlated with the simulations nor with ENSO events.

At mid-latitudes we have selected the area "southern United States". The signal in this area is well pronounced during winter and spring while during sum- 

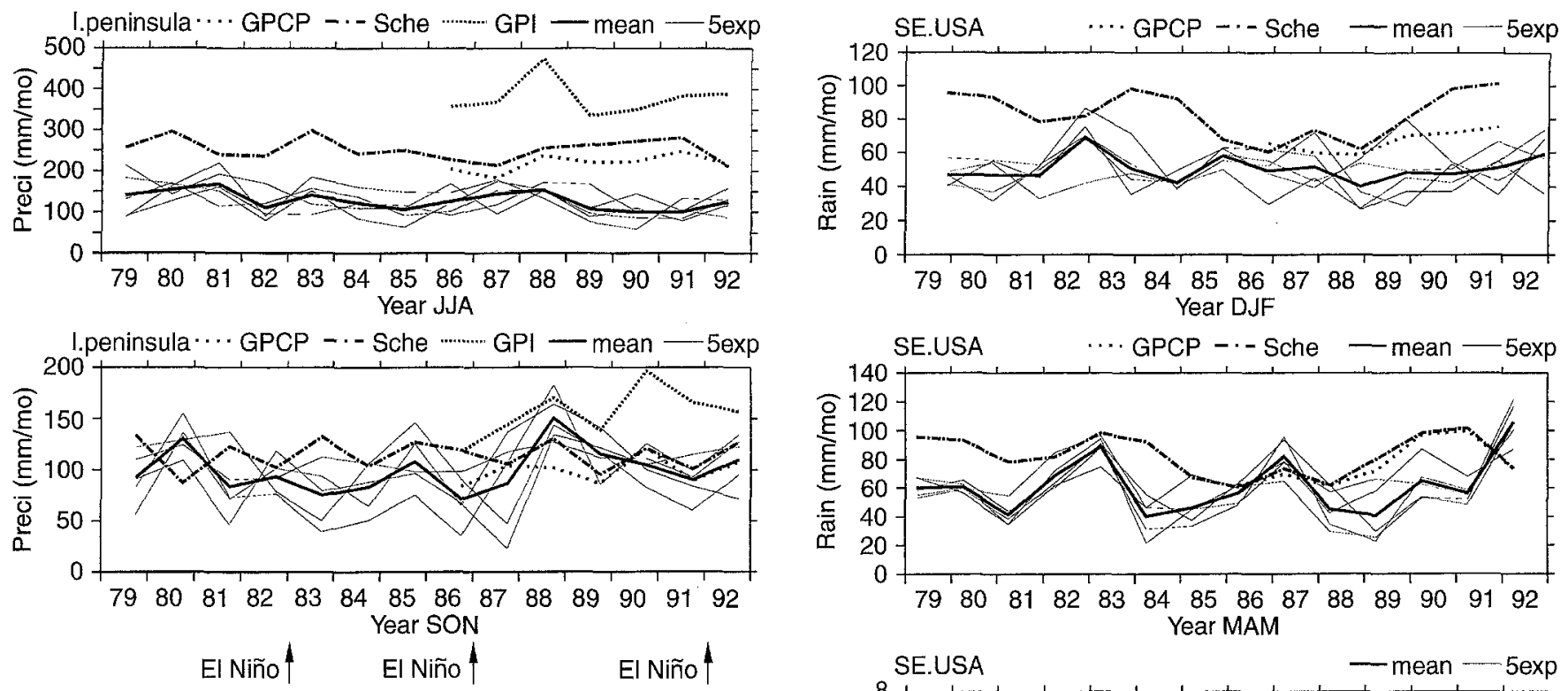

Fig. 16. The same as Fig. 15, but for the Indian Peninsula for JJA and SON
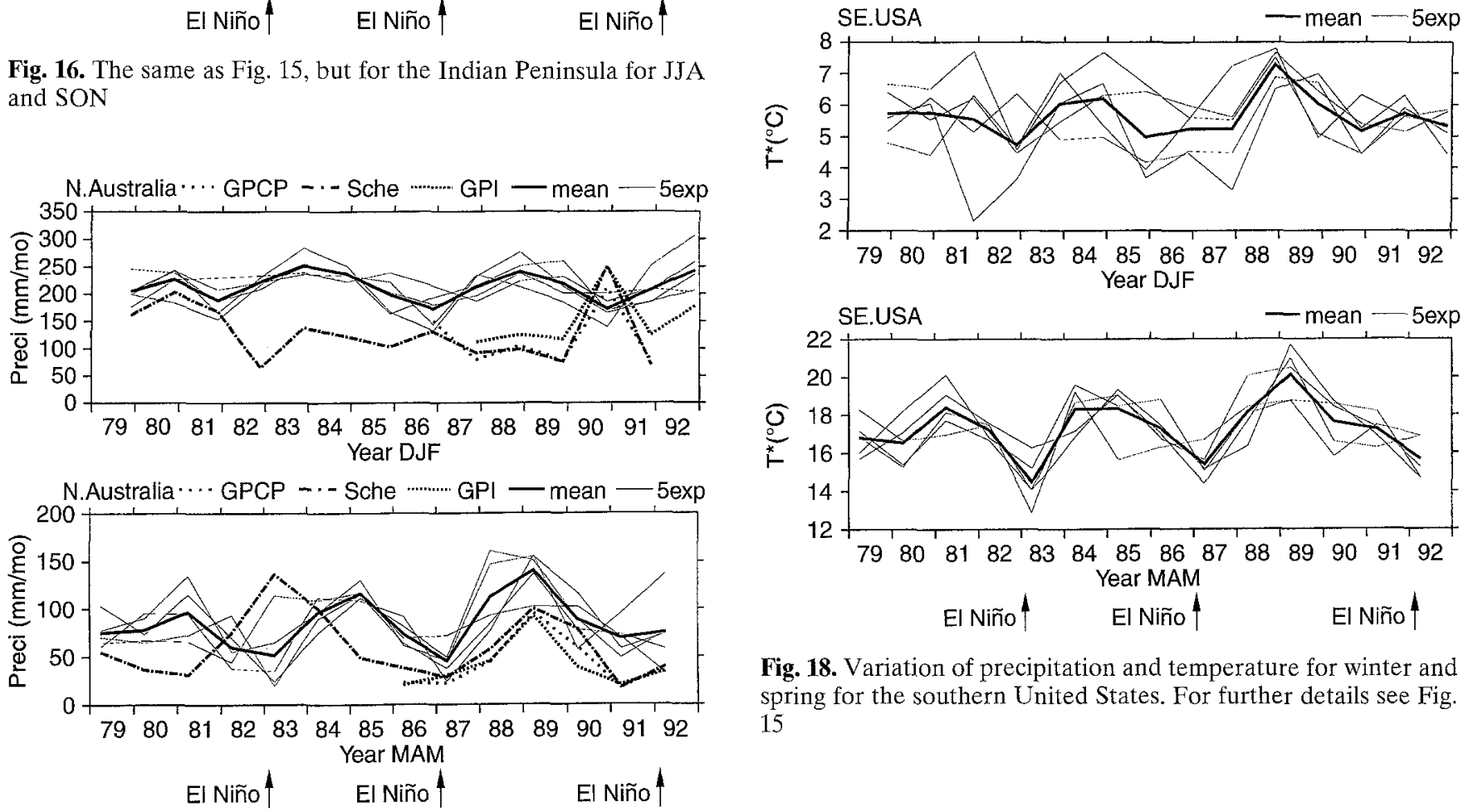

Fig. 18. Variation of precipitation and temperature for winter and spring for the southern United States. For further details see Fig. 15

Fig. 17. The same as Fig. 15, but for northern Australia for DJF and MAM

mer and autumn only a very weak signal can be found. Figure 18 shows precipitation and temperature for winter and spring for southern United States. As indicated, the spring signal is particularly strong with a markedly higher precipitation during the warm events. Temperature variations during spring are opposite to the variations in precipitation, while in winter the variations are less clear and the internal variability is very high. There is a weak indication that the warm events are associated with colder winters. It is interesting to note that all five simulations indicate a very warm summer of 1988 (not shown).

At high-latitudes, the ENSO signal is generally weak, particularly in the eastern hemisphere, but in

some parameters, such as snow depth and probably sea ice, there is a significant signal (e.g. Koslowski and Loewe 1994) with respect to Baltic sea ice. We have selected western Canada and the Scandinavian area for evaluation.

Over western Canada a signal can be detected in all basic parameters, indicating during winter spring milder and dryer conditions during the warm events, and the opposite during the cold events. However the most distinct signal can be found in the snow depth as can be seen in Fig. 19. The snow depth is less during the warm events. The snow variability accumulates the variabilities of precipitation and surface temperature.

In the Scandinavian region the climate conditions are generally colder in winter and spring during the warm events. However, the variability in the Scandinavian sector is larger than over western Canada. To gain a clearer signal than with time series of area 

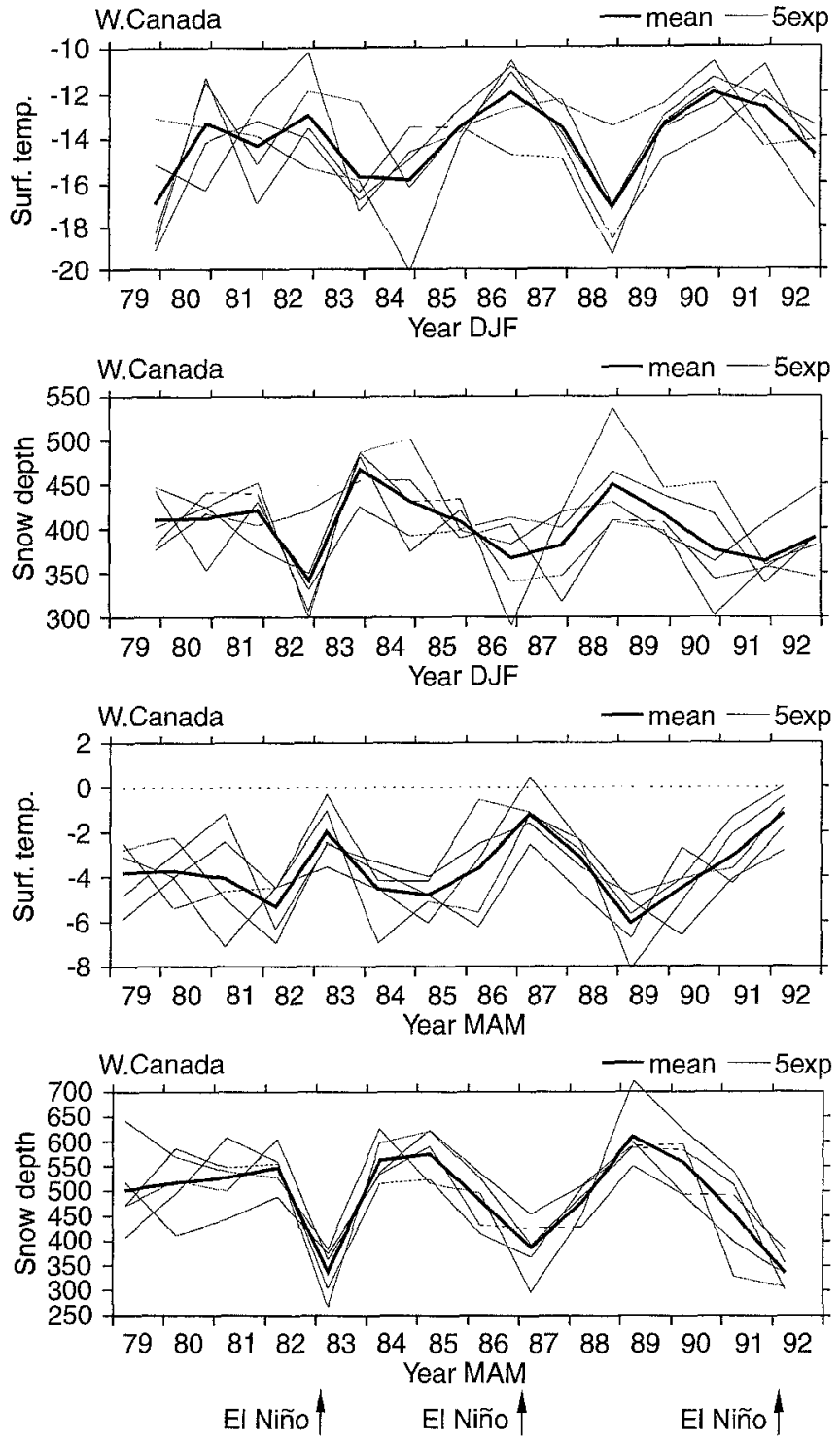

Fig. 19. Simulation of temperature $\left({ }^{\circ} \mathrm{C}\right)$ and snow depth $(\mathrm{mm})$ for western Canada for winter and spring. For further information see Fig. 14

means, we show in Fig. 20 composite maps for Europe of three warm and three cold events respectively, for all five runs.

The effect on the circulation at higher latitudes is less pronounced, but follows a general pattern which we will discuss in terms of mean sea level pressure for the Northern Hemisphere. During the warm events, the Aleutian low is deeper than normal, leading to generally warmer than normal conditions over northwestern United States and southwestern Canada during the winter. The Icelandic low, on the other hand, is weaker than normal and with a tendency for lower than normal pressure over eastern Europe. Such a flow pattern weakens the advection of mild Atlantic airmasses over northern Europe during the winter, thus favouring cold winters. The precipitation in winter over central Europe is higher than normal, indicating that stormtracks take a more southerly route as indi- cated by the lower mean sea level pressure over Europe. It is interesting to note that the model results (Fig. 20) are in good agreement with the empirical results analyzed by Fraedrich and Müller (1992), although their results are based upon ENSO events for the last 100 years. Even if the results from the simulations are statistically significant, this signal has a limited predictive value because of the small amplitude compared to the interannual variability. We also cannot reproduce this signal when using the 15 years of ECMWF analysis data, suggesting that a 15 -year period is too short to give a stable signal.

We have also reviewed the relative importance of the SST in the tropical Pacific versus SST in other ocean basins. It has not been possible to undertake control integrations covering the same length of time. Only studies addressing this issue for shorter experiments of 90 days have been reported by Dümenil et al. (1994), Graham et al. (1994) and Lau and Nath (1994). The relative effect from SST anomalies in the three tropical oceans as well as the extra-tropical areas, separately evaluated with respect to the differences in the $200 \mathrm{hPa}$ velocity potential between 1987 and 1988, demonstrates convincingly that the SST anomalies in the tropical Pacific almost completely dominate the atmospheric response.

It may be relevant in this context to comment on the importance of SST anomalies in the North Atlantic and their influence on climate variations over Europe. Empirical studies (e.g. Kushnir, 1993) have shown that for interannual anomalies of a few years duration, the atmospheric anomalies in the North Atlantic region preceed the ocean anomalies. This can also be seen from the fact that the heat flux in the North Atlantic in winter is negatively correlated with the SST anomalies, demonstrating that the atmosphere is cooling the ocean. This is taking place through a combination of strong surface winds and advection of cold Arctic air masses. This mechanism was originally pointed out by Bjerknes (1962) and has been high-lighted in recent years by Pedersen et al. (1990).

The following sequence of events may be suggested. A warm event intensifies the Aleutian low, which in turn enhances the advection of mild maritime air over western United States and Canada. An intense Aleutian low acts as a stable attractor and is enhanced by advection of cold polar air masses. A corresponding weakening takes place for the Icelandic low, at least partly due to the fact that the polar air masses required for an active cyclone development are finding their way to the Aleutian centre of action more often. Such a configuration reduces the air-sea interaction in the western North Atlantic, resulting in higher than normal SST. The reverse sequence of events happens in case of a cold ENSO event, leading to an intense Icelandic low and colder than normal ocean temperatures in the northwest Atlantic. This means that we may expect a positive correlation between low SST in the western Atlantic and warmer than normal conditions in Western Europe, both patterns being forced by a stronger than normal Icelandic low. 
El Niño

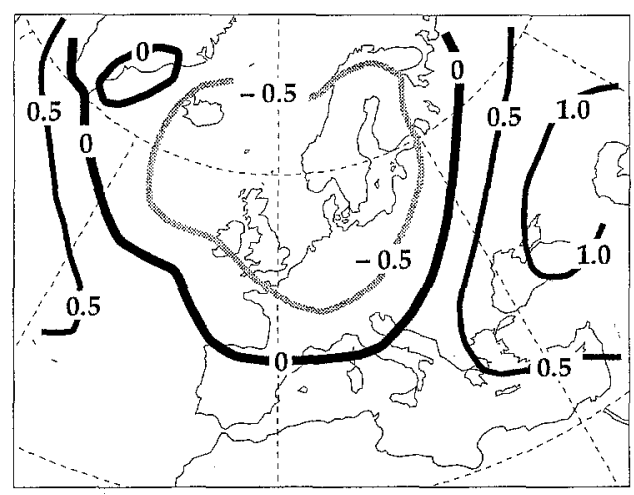

La Niña

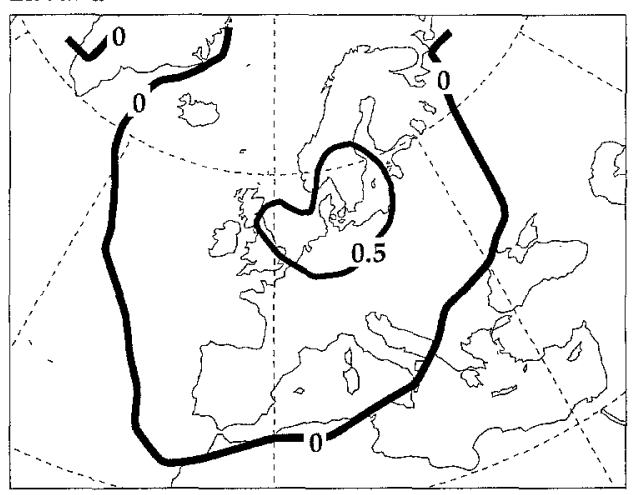

Simulated
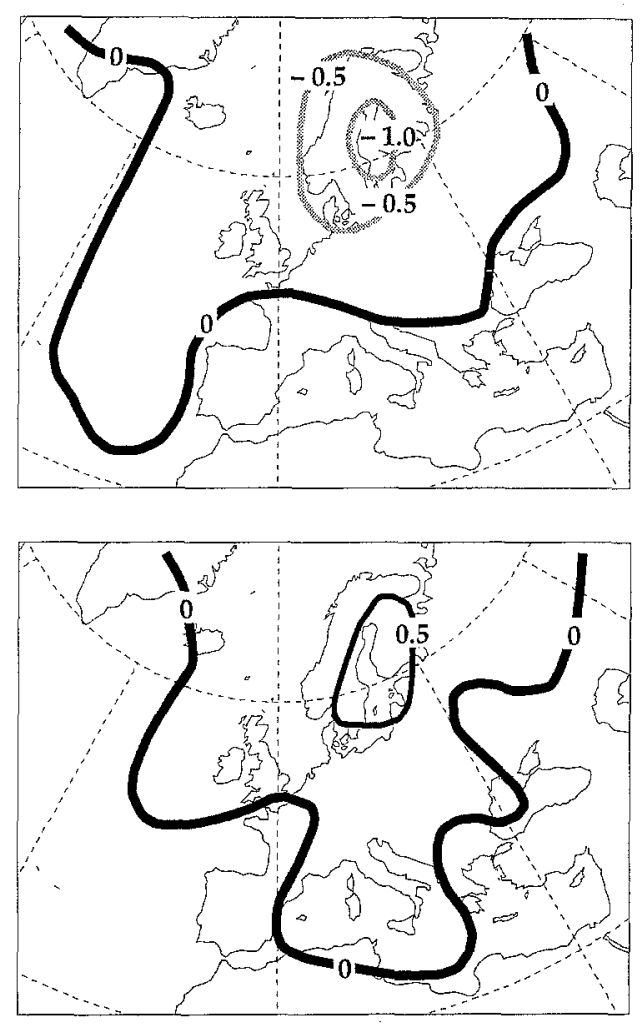

Observed
Fig. 20. Simulated temperature at $850 \mathrm{hPa}($ left $)$ and observed surface temperature (right) for the ENSO signal for the European area. Observations according to Fraedrich and Müller (1992). Unit ${ }^{\circ} \mathrm{C}$

\section{Conclusions}

We have examined the ability of the ECHAM3 model to simulate the atmospheric response to the SST forcing in the 14-year period 1979-1992, that contains three El Niño and La Niña events. The reproducibility of the SST signal has been investigated by carrying out five separate experiments, starting from different atmospheric initial states.

The low frequency tropical circulation is strongly determined by the SST anomaly pattern, which contributes to a major part of the tropical variance. The model reproduces a Southern Oscillation pattern, strongly resembling the observed one. During an El Niño event, the suptropical jet streams in both hemispheres are intensified and weak upper tropospheric easterlies appear over the equator. The strengthening of the subtropical jets can be noticed all around the globe as well as the associated tropical warming pattern. A reverse response pattern can be seen in the cold La Niña events, with upper equatorial westerlies in the eastern Pacific and a poleward movement and weakening of the subtropical jets.

While the tropical circulation is strongly coupled to the SST patterns, the atmospheric circulation at middle- and high-latituldes is mostly dominated by the large-scale dynamical circulation, and the patterns in the observed SST run are very similar to the patterns obtained in the climate SST run. The tropospheric correlation pattern associated with the North Pacific centre of action and the North Atlantic centre of action are remarkedly similar in the two cases, and thus quite insensitive to the actual SST pattern. It is strongly suggested that atmospheric dynamics on their own can generate persistent extreme circulation patterns, dominating a whole season.

However, the ENSO events do modulate the atmospheric circulation patterns at middle- and high-latitudes thus providing a predictability signal also here. It is suggested from the model runs that northwestern United States and western Canada are normally warmer during the warm ENSO phase while northern Europe is warmer than normal during the ENSO cold phase. The reason is advection of warm air due to a more intense Pacific low than normal during the warm ENSO phase and a more intense Icelandic low than normal during the cold ENSO phase.

We have assessed the regional predictability by specifically examining seven different regions: NINO3, northeast Brazil, the Indian Peninsula, northern Australia, southern United States, western Canada and Scandinavia. The tropical regions, with the exception of India, have a very pronounced ENSO response in the precipitation pattern, particularly during the boreal winter and spring. The pattern is also highly reproducible, suggesting high potential predictability. Over southern United States as well as over Morocco, northern Algeria (not shown) and southwestern Asia, there is a very strong signal for spring precipitation, with significantly higher precipitation during the warm ENSO events. The high latitude response is generally weaker, in particular for the Scandinavian area, but a weak signal is noticed in the winter temperature.

Successful ENSO predictions will require accurate 
predictions of the sea surface temperature. To concentrate the development of realistic coupled models on the tropical Pacific will be the most important task for modellers in the years to come. Prior to reliable fully coupled models, hybrid models, a combination of an SST anomaly model and an atmospheric GCM (Bengtsson et al. 1993; Barnett et al. 1994) are a useful starting point.

Ensemble prediction, using different atmospheric initial states, appears to be the most rational approach to operational ENSO prediction. The size of such an ensemble, in view of the high internal atmospheric variability at higher latitudes, may have to be larger than the five cases we have investigated here.

Acknowledgements. The authors are indebted to their colleagues at Max-Planck-Institut fuir Meteorologie in Hamburg and at the German Climate Computing Centre for constructive discussions and generous technical assistance.

\section{References}

Arpe K, Bengtsson L, Dümenil L, Roeckner E (1994a) The hydrological cycle in the ECHAM3 simulations of the atmospheric circulation. In: Debois M, Desalmand F (eds) Global Precipitation and Climate Change. NATO ASI Series Vol I 26:361-377

Arpe K, Bengtsson L, Dümenil L, Giorgetta M (1994b) Variability of the Indian monsoon in the ECHAM3 model, Part II: sensitivity to sea surface temperatures of the northern Indian ocean, soil moisture over Eurasia and the stratospheric QBO. Conf Monsoon Variability, Trieste May 1994, WCRP-Rep 84, WMO/TD-No. 619:621-628

Asselin R (1972) Frequency filter for time integrations. Mon Weather Rev 100:487-490

Barnett TP, Bengtsson L, Arpe K, Flügel M, Graham N, Latif M, Ritchie J, Roeckner E, Schlese U, Schulzweida U, Tyree M (1994) Forecasting global ENSO-related climate anomalies. Tellus 46A:381-397

Bengtsson L., Schlese U, Roeckner E, Latif M, Barnett TP, Graham N (1993) A two-tiered approach to long-range climate forecasting. Science 261:1026-1029

Bengtsson L, Botzet M, Esch M (1994a) Hurricane-type vortices in a general circulation model. Tellus 47A:175-196

Bengtsson L (1994b) Wie gut können wir das Klima mit einem numerischen Modell der allgemeinen Zirkulation simulieren? Symp Observation und Simulation der Atmosphäre, Potsdam. 6-7 May 1993. Ann Meteorol 29:93-132

Berlage HP (1966) The Southern Oscillation and world weather. K Ned Meteorol Inst Meded Verh 88:1-152

Bjerknes J (1962) Synoptic survey of the interaction of sea and atmosphere in the North Atlantic. Geofys Publ 24:115-145

Brankovic C, Palmer TN, Ferranti L (1994) Predictability of seasonal atmospheric variations. J Clim 7:217-237

Brinkop S (1991) Inclusion of cloud processes in the ECHAM PBL parameterization. In: R Sausen (ed) Studying climate with the ECHAM atmospheric model. Large-scale atmospheric modelling, Rep 9, 5-14, Meteorologisches Institut, Universität Hamburg, Germany

Brinkop S (1992) Parameterisierung von Grenzschichtwolken für Zirkulationsmodelle. Berichte aus dem Zentrum für Meeresund Klimaforschung, Reihe A. Meteorologie, Nr. 2, Meteorologisches Institut der Universität Hamburg, $77 \mathrm{pp}$

Cane MA (1992) Tropical Pacific ENSO models: ENSO as a mode of the coupled system. In: Trenberth K (ed), Climate system modeling, pp 583-614
Cubasch U (1985) The mean response of the ECMWF global model to the El Niño anomaly in extended range prediction. Atmos-Ocean 23:43-66

Delecluse P, Servain J, Levy C, Arpe K, Bengtsson L (1994) On the connection between the 1984 Atlantic warm event and the 1982-1983 ENSO. Tellus 46A:448-464

Doberitz R (1968) Cross-spectrum analyses of rainfall and sea temperature at the equatorial Pacific Ocean. Bonn Meteorol Abh 8:1-61

Dümenil L, Todini E (1992) A rainfall-runoff scheme for use in the Hamburg GCM. In: O'Kane JP (ed) Advances in Theoretical Hydrology. European Geophysical Society Series on Hydrological Sciences, 1, Elsevier, pp 129-157

Dümenil L, Arpe K, Bengtsson L (1994) Variability of the Indian Monsoon in the ECHAM3 model. Part I: MONEG and AMIP experiments. Conf Monsoon Variability, Trieste, May 1994, WCRP-Rep 84, WMO/TD-No. 619:609-620

Fraedrich K, Müller K (1992) Climate anomalies in Europe associated with ENSO extremes. Int J Clim 12:25-31

Gates WL (1992) AMIP the atmospheric model intercomparison project. Bull Am Meteorol Soc 73 (12):1962-1970

Glantz MH, Katz RW, Nicholls N (eds) (1991) Teleconnections linking worldwide climate anomalies. Cambridge University Press, Cambridge, UK

Graham NE, Ponater M, Barnett TP, Wilde R, Schubert S (1994) On the roles of tropical and mid-latitude SSTs in forcing interannual to interdecadal variability in the winter Northern Hemisphere circulation. J Clim 7:1416-1441

Hense A, Kerschgens M, Raschke E (1982) An economical method for computing radiative transfer in circulation models. Q J R Meteorol Soc 108:231-252

Hildebrandsson HH (1897) Quelque recherches sur les centres d'action de l'atmosphere. K Sven Vetenskaps Akad Handl $29: 1-33$

Hoerling M, Blackmon M, Ting M (1992) Simulating the atmospheric response to the 1985-87 EI Niño cycle. J Clim 5:669682

Ichiye T, Petersen J (1963) The anomalous rainfall of the 1957-58 winter in the equatorial central Pacific arid area. J Meteorol Soc Japan 41 : 172-182

Janowiak JE, Arkin PA (1991) Rainfall variations in the tropics during 1986-1989, as estimated from observations of cloudtop temperature. J Geophys Res 96:3359-3373

Kang IS, Lau NC (1987) Principal modes of atmospheric variability in model atmospheres with and without sea surface temperature forcing in the tropical Pacific. J Atmos Sci 43:27192735

Kushnir Y (1993) Interdecadal variations in North Atlantic sea surface temperature and associated atmospheric conditions. J Clim 7:141-157

Lau NC (1985) Modeling the seasonal dependence of atmospheric responses to observed El Niños 1962-1976. Mon Weather Rev 113:1970-1996

Lau NC, Nath MJ (1994) A modelling study of the relative roles of tropical and extratropical SST anomalies in the variability of the global atmosphere-ocean system. J Clim 7:1184-1207

Laursen L, Eliasen E (1989) On the effects of damping mechanisms in an atmospheric general circulation model. Tellus $41 \mathrm{~A}: 385-400$

Louis JF (1979) A parametric model of vertical eddy fluxes in the atmosphere. Boundary-Layer Meteorol 17:187-202

May W, Bengtsson L (1994) On the intra-seasonal variability within the extra-tropics in a general circulation model and observational data. Proc Seventeenth Stanstead Seminar Lennoxville, Canada, Shepherd T (ed) 139-147

Miller MJ, Palmer TN, Swinbank R (1989) Parameterization and influence scale of sub-grid scale orography in general circulation and numerical weather prediction models. Meteorol Atmos Phys 40:84-109 
Miller MJ, Beljaars A, Palmer TN (1992) The sensitivity of the ECMWF model to the parameterization of evaporation from tropical oceans. J Clim 5:418-434

Palmer TN, Shutts GJ, Swinbank R (1986) Alleviation of a systematic westerly bias in general circulation and numerical weather prediction models through an orographic gravity wave drag parameterization. Q J R Meteorol Soc 112:10011031

Palmer TN, Molteni F, Mureau R, Buizza R, Chapelet P, Tribbia J (1993) Ensemble prediction. (Available from ECMWF)

Pedersen K, Ese T, Kaneström I (1990) Persistent anomalies of sea-surface temperatures in the North Atlantic. Z Meteorol 40(4):229-23

Philander SGH (1989) El Niño, La Niña, and the Southern Oscillation. Vol 46, International Geophysical Series, Academic Press

Ponater M, König I, Sausen R, Sielmann F (1994) Circulation regime fluctuations and their effect on intraseasonal variability in the ECHAM climate model. Tellus 46A:265-285

Rasmussen EM, Carpenter TH (1983) The relationship between eastern equatorial Pacific sea surface temperature and rainfall over India and Sri Lanka. Mon Weather Rev 111:517-528

Reynolds RW (1988) A real-time global sea surface temperature analysis. J Clim 1:75-86

Rockel B, Raschke E, Weynes B (1991) A parameterization of broad band radiative transfer properties of water, ice and mixed clouds. Beitr Phys Atmos 64:1-12

Roeckner E, Arpe K, Bengtsson L, Brinkop S, Dümenil L, Esch M, Kirk E, Lunkeit F, Ponater M, Rockel B, Sausen R, Schlese U, Schubert S, Windelband M (1992) Simulation of the present-day climate with the ECHAM model: Impact of model physics and resolution. Max- Planck-Institut für Meteorologie, Hamburg, Rep 93

Roeckner E, Rieland M, Keup E (1991) Modelling of cloud and radiation in the ECHAM model. ECMWF/WCRP Workshop on Clouds, Radiative Transfer and the Hydrological Cycle, ECMWF, Reading, UK 199-222

Ropelewski CE, Halpert MS (1987) Global and regional scale precivitation and temperature patterns associated with the El Niño/Southern Oscillation. Mon Weather Rev 115:16061626

Rudolf B, Hauschild H, Reiß M, Schneider U (1992) The calculation of areal mean precipitation totals on a 2.5 grid by an objective analyses method. Meteorol Z 1:32-50

Schemm J, Schubert S, Terry J, Bloom S (1992) Estimates of monthly mean soil moisture for 1979-1989. NASA Technical Memo 104571, 262 pp

Shukla J, Mooley DA (1987) Empirical prediction of summer monsoon rainfall over India. Mon Weather Rev 115:695703

Sundqvist H (1978) A parameterization scheme for non-convective condensation including prediction of cloud water content. Q J R Meteorol Soc 104:677-690

Tiedtke M (1989) A comprehensive mass flux scheme for cumulus parameterization in large-scale models. Mon Weather Rev 117:1779-1800

Trenberth KE, Shea DJ (1987) On the evolution of the Southern Oscillation. Mon Weather Rev 112:326-332

Walker GT (1923) Correlation in seasonal variations in weather. VIII. A preliminary study of world weather. Mem Indian Meteorol Dep 24(4):75-131

Walker GT (1924) Correlation in seasonal variations in weather. IX. A further study of world weather. Mem Indian Meteorol Dep 24(9):275-332

Walker GT (1928) World weather III. Mem R Meteorol Soc 2:97-106

Villwock A (1994) Enso induzierte Variabilität im Indischen Ozean. Examensarbeit Nr. 22, Max-Planck-Institut für Meteorologie, Hamburg, Germany 